Purdue University Purdue e-Pubs

2013

\title{
International Standardization Compliance in Aviation
}

Tyler Brogden Spence

Purdue University

Follow this and additional works at: https://docs.lib.purdue.edu/open_access_theses

Part of the Aerospace Engineering Commons, International Relations Commons, and the Public Policy Commons

\section{Recommended Citation}

Spence, Tyler Brogden, "International Standardization Compliance in Aviation" (2013). Open Access Theses. 58.

https://docs.lib.purdue.edu/open_access_theses/58

This document has been made available through Purdue e-Pubs, a service of the Purdue University Libraries. Please contact epubs@purdue.edu for additional information. 


\section{PURDUE UNIVERSITY \\ GRADUATE SCHOOL \\ Thesis/Dissertation Acceptance}

This is to certify that the thesis/dissertation prepared

By Tyler Brogden Spence

Entitled
INTERNATIONAL STANDARDIZATION COMPLIANCE IN AVIATION

For the degree of

Master of Science

Is approved by the final examining committee:

Dr. Richard O. Fanjoy

Chair

Dr. Chien-Tsung Lu

Dr. Stewart W. Schreckengast

To the best of my knowledge and as understood by the student in the Research Integrity and

Copyright Disclaimer (Graduate School Form 20), this thesis/dissertation adheres to the provisions of Purdue University's "Policy on Integrity in Research" and the use of copyrighted material.

Approved by Major Professor(s): Dr. Richard O. Fanjoy

Approved by: Dr. Richard O. Fanjoy

$04 / 17 / 2013$

Head of the Graduate Program 


\title{
INTERNATIONAL STANDARDIZATION COMPLIANCE IN AVIATION
}

\author{
A Thesis \\ Submitted to the Faculty \\ of \\ Purdue University \\ by \\ Tyler B. Spence \\ In Partial Fulfillment of the \\ Requirements for the Degree \\ of \\ Master of Science
}

May 2013

Purdue University

West Lafayette, Indiana 
For my parents, Roland and Cara Lee Spence 


\section{ACKNOWLEDGEMENTS}

I would like to acknowledge the graduate program department head, my major professor, and my committee chair, Dr. Richard O. Fanjoy. I am extremely grateful for his continuous support for my graduate studies and for his support of the entire graduate aviation department. I would also like to thank my other committee members Dr. ChienTsung Lu and Dr. Stewart W. Schreckengast for their expertise and support through the entire graduate process as well. In addition, I would like to thank Jeffei Li for providing the ICAO data for my research. 
TABLE OF CONTENTS

Page

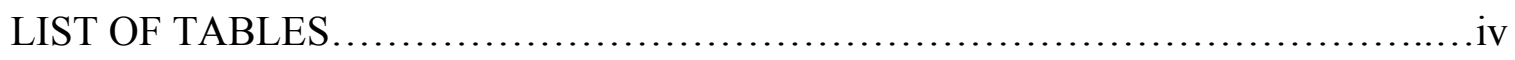

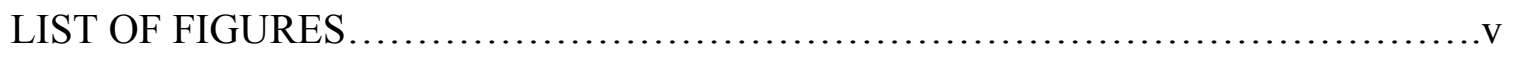

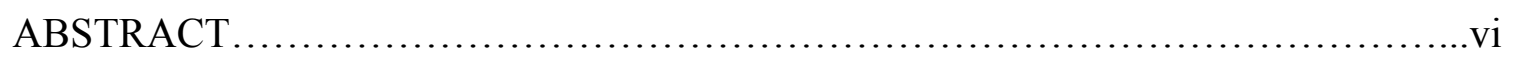

CHAPTER 1. INTRODUCTION.................................................

$1.1 \quad$ Problem Statement...................................................

$1.2 \quad$ Research Question................................................2

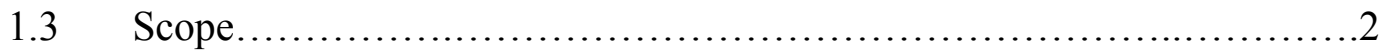

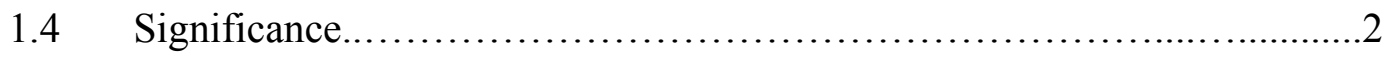

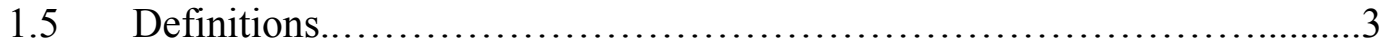

1.6 Assumptions...................................................4

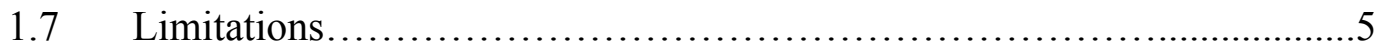

$1.8 \quad$ Delimitations.........................................................

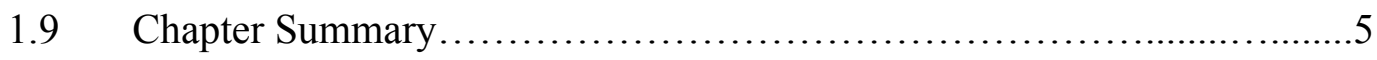

CHAPTER 2. LITERATURE REVIEW ........................................

2.1 International Civil Aviation Organization...................................9

2.2 The Freedoms of the Air........................................... 11

2.3 International Objectives........................................ 13 
2.4 ICAO, Best Option for Global Safety ................................. 15

$2.5 \quad$ Aviation Safety Trends............................................18

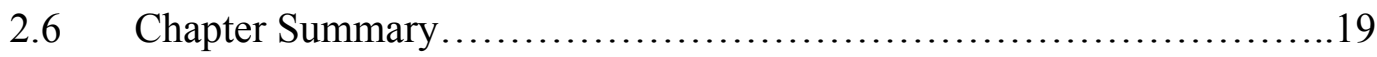

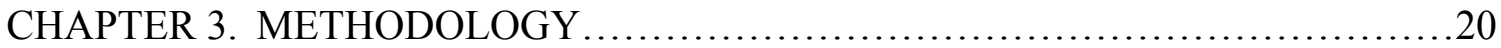

3.1 Research Type and Framework.............................................20

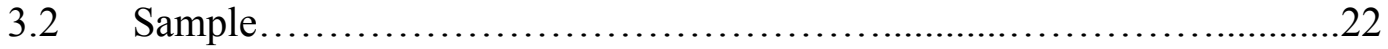

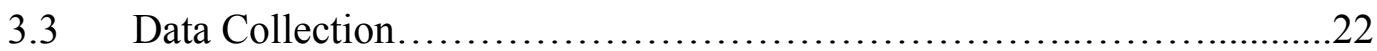

3.4 Testing Method.........................................................24

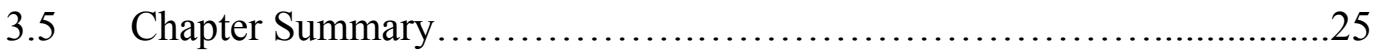

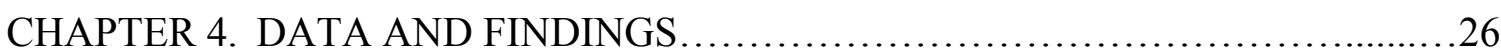

$4.1 \quad$ Data Analysis......................................................

4.2 Regional Variance.................................................... 30

$4.3 \quad$ Covariate Analysis.................................................

CHAPTER 5. CONCLUSIONS AND RECOMMENDATIONS.......................38

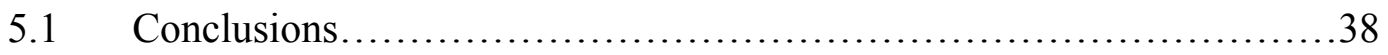

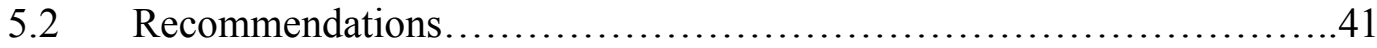

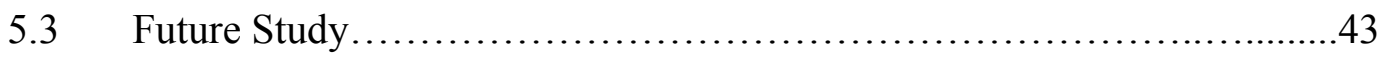

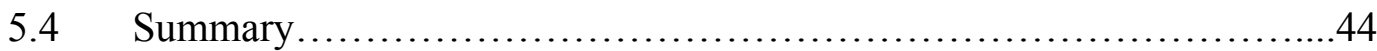

LIST OF REFERENCES ....................................................................

\section{APPENDICES}

Appendix A: ICAO Member State Data.......................................49

Appendix B: ICAO Member States Not Considered...........................52 


\section{LIST OF TABLES}

Table Page

Table $4.1 \quad$ Excel ICAO Member State Data Sample................................27

Table $4.2 \quad$ State Name and Economic Status.................................. 34 


\section{LIST OF FIGURES}

Figure

Page

Figure 4.1 Scatter Plot of Total Departures and Total Fatalities Between States.....29

Figure 4.2 Scatter Plot Comparing Effective Implementation Rate and Fatality per Departure......................................................

Figure $4.3 \quad$ Number of ICAO Member States In Each Region..................... 31

Figure 4.4 Average Number of Fatalities per Region...........................32

Figure 4.5 Average Commercial Departures by Region...........................32

Figure 4.6 Scatter Plot of Effective Implementation Rate and Average GDP.......34

Figure 4.7 Effective Implementation Rate Compared to Average GDP by Economic

Status............................................................ 


\begin{abstract}
Spence, Tyler B. M.S., Purdue University, May 2013. International Standardization Compliance in Aviation. Major Professor: Dr. Richard O. Fanjoy.
\end{abstract}

The commercial aviation industry is global in the sense that passengers travel around the world from destination to destination. It is also global in that the states of the world (countries) regulate the industry domestically and internationally. There is a unique stage where the world comes together to promote aviation, discuss ideas and establish international standards. This stage is the International Civil Aviation Organization (ICAO). The 191 current member states signed treaties acknowledging their commitment to abiding by the standards and practices established by ICAO. No state is 100 percent compliant with international standards, however, and the purpose of this paper is to explore the relationship between the fulfillment of compliance by individual member states and the safety of the commercial aviation industry in terms of fatality rates. Analysis of the results suggested that there is a relationship between compliance and fatalities, as compliance percentage increases the fatality rate decreases. Further analysis indicated the results were statistically significant regardless of the wealth of a state or size of a state's commercial operation. 


\section{CHAPTER 1. INTRODUCTION}

International organizations (IOs), more specifically International Governmental Organizations (IGOs) and Non-Governmental Organizations (NGOs), are prominent frameworks for negotiations and diplomacy among the states of the world. There are approximately 238 international organizations that are focused on an array of issues from humanitarian policies to environmental concerns. Some of the more prominent IOs include the United Nations (UN), World Health Organization (WHO) and North Atlantic Treaty Organization (NATO) (Barnett \& Finnemore, 2004). Barnett and Finnemore (2004) explain, "States create IOs to solve problems of incomplete information, transactions costs, and other barriers to welfare improvements for their members" (p. 2). As the world has become more globalized, international organizations have been created to help make industries compete equitably and fairly. In the aviation industry, the International Civil Aviation Organization (ICAO) was chartered to help enable a strong and safe global aviation industry as commercial flights became a realistic means for travel.

\subsection{Problem Statement}

The purpose of this study is to explore the link between participation in international organizations such as ICAO and a safe aviation history. Analysis of this 
link could provide insight into the impact of state compliance with ICAO standards. This research will focus on compliance with international aviation regulations and if such compliance makes a difference in the aviation industry.

\subsection{Research Question}

In order to address the issue of ICAO standardization among states, the research question to be explored is: "Is there a relationship between compliance with ICAO global aviation standards and a safe commercial aviation industry?"

\section{$1.3 \underline{\text { Scope }}$}

This research is focused on the commercial aviation industry and compliance rates of individual states with ICAO standards. The research attempts to relate aviation industry safety to the Effective Implementation percentage of an individual state's aviation regulations as guided by ICAO standards and procedures. The Effective Implementation percentage is measured by the average value of eight critical areas determined by ICAO. The analysis of the research will only attempt to determine whether or not there is indeed a link between a state's standards compliance and aviation safety record.

\subsection{Significance}

Flights around the world carry passengers and cargo on a daily basis: aviation is a global industry. ICAO is the international organization that oversees standards and practices for participating states in an attempt to make the safest and most efficient 
industry possible. There are currently 191 participating members in ICAO that agree to strive for the same goals. When an airline has an accident anywhere in the world it affects the entire industry negatively, especially when fatalities are involved. Through continuous compromise and negotiation, the participating states in ICAO have created a collection of practices that intend to create a safer aviation industry. Intentions, however, do not ensure that every state participating in ICAO implements all or any of the policies recommended by ICAO. Axelrod and Keohane (1985) explain that international regimes rarely have the power to enforce the rules or guarantee compliance to standards.

"Nevertheless, since governments with good reputations can more easily make agreements than governments with bad ones, international regimes can help to facilitate cooperation by making both easier and desirable to acquire a good reputation" (Axelrod and Keohane, 1985, p. 250). Even though member states sign treaties agreeing to certain standards, ICAO does not have the authority to force compliance. States are sovereign and ultimately can choose to implement the standards and policies in their best interest. Even with the best of intentions, fatalities still occur attributable to both unpreventable and preventable circumstances. The fact that preventable accidents still occur indicates that there is room for improvement.

\subsection{Definitions}

Effective implementation - the indicator used to benchmark state audit results. It is a percentage of compliance derived by the ICAO Audits that is calculated by taking the total number of satisfactory protocol questions and dividing it by the total number of applicable protocol questions (ICAO, 2010a) 
Liberal institutionalism - a theory of international relations that says institutions are "created by states because of their anticipated effects on patterns of behavior" (Keohane \& Martin, 1995, p. 46). "International institutions are created in response to state interests, and that their character is structured by the prevailing distribution of capabilities (Keohane \& Martin, 1995, p. 47)

Protocol questions - Questions divided into eight specific areas used by ICAO to determine the Effective Implementation percentage for the USOAP (ICAO, 2010a)

State - a sovereign entity recognized by international communities, also known as countries or nation-states. State is the preferred term and will be used throughout this study

Universal Safety Oversight Audit Programme - a tool used by ICAO to determine the implementation and effectiveness of a member state's compliance to international standards (ICAO, 2011)

\subsection{Assumptions}

The following assumptions are inherent to the study:

- The participating member states in ICAO represent nearly all commercial airline traffic.

- Proper regulation and oversight can help prevent accidents and incidents.

- Regulations and policies affect aviation practices.

- Individual states report accurate statistics.

- Individual states are equally concerned about safety in aviation. 


\subsection{Limitations}

The following limitations are inherent to the study:

- This study is limited to the data provided between 2005-2012 for ICAO compliance and fatalities.

- The primary data is limited to that obtained from ICAO

- The research is limited to comparing fatality rates to number of departures in a given state.

- The research is limited to 177 states participating in ICAO.

\subsection{Delimitations}

The following delimitations are inherent to the study:

- This study does not take into account states that are not members of ICAO but have (potentially compliant) commercial aviation programs.

- This study does not take into account the specific causes of accidents as determined by an investigation.

- This study does not examine the specific ICAO regulations such as maintenance or licensing requirements of different states.

\subsection{Chapter Summary}

This chapter establishes the foundation of this paper. Included are descriptions of the background, problem, research question, scope significance, assumptions, limitations 
and delimitations. The next chapter reviews in detail the existing research and historical international agreements that shape the context of this paper. 


\section{CHAPTER 2. LITERATURE REVIEW}

International organizations (IOs) are formed through cooperation among states and are based on a central global idea. The effect of globalization is that, as of 2004, there were more than 238 international organizations playing a role in world affairs (Barnett \& Finnemore, 2004). International organizations such as the United Nations, the World Health Organization, and the World Trade Organization have been established to provide forums for states to negotiate issues and solve global problems simultaneously.

Globalization is extremely important to aviation. People are able to travel around the world in a matter of hours and, in the hopes of creating an even more interconnected world, states have developed international organizations to specifically facilitate standards and practices for the aviation community. The ultimate goal of these organizations, and the industry as a whole, is to provide for the most efficient yet safest travel possible.

The international relations theory of liberal institutionalism, or institutionalism, can be applied to aviation in order to help understand why states make decisions regarding standardization and compliance with international practices. Institutionalism is a theory of social science that seeks to discover why states behave the way they do. Two researchers who popularized the theory of institutionalism, Keohane and Martin (1995) state: 
When state elites do not foresee self-interested benefits from cooperation, we do not expect cooperation to occur, or the institutions that facilitate cooperation to develop. When states can jointly benefit from cooperation, on the other hand, we expect governments to attempt to construct such institutions. (pp. 42-43)

There are four basic assumptions of the theory that define this theory: the world is anarchic, every state has a military capability, a state is uncertain about the actions of others, and survival is the most basic necessity of a state (Keohane, 1984). Anarchy refers to the lack of a central government in world politics and "not to a denial that an international society-albeit a fragmented one-exists" (Axelrod \& Keohane, 1985, p. 226). The individual state is the highest order of power in the international realm and a state does not know the intentions of another. Therefore, central to this theory, is the idea that states will cooperate out of necessity. "Cooperation in world politics seems to be attained best not by providing benefits unilaterally to others, but by conditional cooperation" (Axelrod \& Keohane, 1985, p. 249). This theory can be used to explain why international organizations such as ICAO are formed and used as an arena for multilateral cooperation. Axelrod and Keohane also explain, "International regimes do not substitute for reciprocity; rather, they reinforce and institutionalize it. Regimes incorporating the norm of reciprocity delegitimize defection and thereby make it more costly" (p. 250). Compromise among states is not uncommon as states may even forego an immediate short-term benefit to compromise for a long-term benefit. This systematic evaluation to determine compromise makes the institutions effective and unique in international politics. 
The current research must be framed with respect to the ultimate beliefs and goals that the international community agrees upon because negotiations and multilateral discussions are paramount to a successful organization. The two most important international organizations impacting standardization and practices in aviation are the International Civil Aviation Organization (ICAO) and the International Air Transport Association (IATA). With the primary goals of efficient and safe travel in aviation and the belief that cooperation is crucial on an international level, government involvement is imperative. Aviation incidents and accidents in aviation can reflect poorly on the state from which an aircraft operated, the state in which an incident occurs, and the airline itself. There are considerable costs associated with an accident, including the loss of human life. Achieving the safest aviation system possible is a shared goal across the industry.

\subsection{International Civil Aviation Organization}

ICAO was chartered on December 7, 1944 and was officially ratified by a majority of the original 52 signatories on April 5, 1947, becoming an official agency of the United Nations (ICAO, n.d.a). The first meeting that established ICAO was negotiated in Chicago during, what was appropriately called, the Chicago Convention (Talmon, 2009). Today there are 191 participating states representing nearly every state in the international aviation community as well as the world. Nayar (1995) describes the events of the convention as successful despite natural conflicts that arose through diplomatic discourse. 
The participating states were able to agree on several key issues regarding "freedoms of the air." However, these states also stipulated that sovereignty of individual states is essential (FAA, 1994). This means that even though all of the participating states agree to adhere to the policies as set forth by ICAO, they do so at will and without commitment or infringement on their authority. There is no higher authority than the state regarding regulation and enforcement. This poses problems for all international organizations, not just ICAO, because it means that the organization does not have any "hard power" to exert its will on member states. Should a member state not choose to abide by a certain policy then the most stringent action that can be taken is a vote to ban the member from the organization. Ultimately, the expectation is that all of the states willingly accept the policies and procedures of the organization because each state has agreed to adhere to them. For ICAO, rules and policies are developed to increase the safety and efficiency of the aviation industry.

The United States supports ICAO and was one of the original charter members. The Federal Aviation Administration (FAA) (1994) through advisory circular 91-70 states:

As a charter member of ICAO, the United States has fully supported the organization's goal from its inception, being especially concerned with technical matters. Through ICAO, the United States works to achieve the highest practical uniform air regulations, standards and procedures for aircraft, personnel, airways, and aviation services throughout the world. At the same time the United States depends upon ICAO to ensure that navigation facilities, airports, weather, and radio services provided by other nations meet international standards (FAA, 1994, p. 5). 
Currently, as the sole remaining superpower in the world after the fall of the Soviet Union, the United States has a presence in most of the world. Kupchan states, "As the new millennium opened, the West was not only running the show, but appeared to have finally prevailed against its many antagonists" (pp. 1-2). Because it has such a high profile, the United States is a key player in world politics and this includes participating in and adopting the policies of world organizations. In the United States, the FAA uses standards and procedures from ICAO to frame its own practices and maintain a safe aviation industry.

\subsection{The Freedoms of the Air}

A state that agrees to follow the principles of ICAO is making a statement to the other states on how it believes the aviation industry should operate. The initial group of "five freedoms of the air" is one of the many outcomes of the Chicago Convention in 1944. These principles set the framework for how member states set their own national policies with regards to international aviation. According to Milde (2008), freedoms, "in order to stress their exceptional nature," can be described as privileges that represent "the basic and elementary proviso for the 'right to fly' internationally" (p. 104).

These five freedoms are derived from the International Air Services Transit Agreement and the International Air Transport Agreement (Milde, 2008). The first two freedoms granted by the Air Services Transit Agreement are the right to fly over a state without landing and the right to stop in a state for non-traffic reasons such as refueling or emergencies. These are important for international travel because states are able to fly without regional limitations. These freedoms allow for aircraft to fly directly from 
Canada to Mexico, and in the process have the guaranteed right to be able to fly over the United States without interference. In the same scenario, should an emergency occur while over the United States, the second freedom would allow that aircraft to land in the United States without fear of punishment from the United States.

Three additional freedoms added by the Air Transport Agreement are: the right to allow passengers to disembark the aircraft in another state as long as they boarded in the state in which the aircraft is operated, the right to allow passengers to board in a foreign state if the aircraft is returning to the state from which it is operated, and the right to board and disembark any passengers from any state in any destination (Milde, 2008). This means that any signatory state has the right to allow passengers from any state to board an aircraft and then be allowed to travel to their destination in any state on that same aircraft.

ICAO recognizes nine freedoms of the air; however, these have only been included in some bilateral or multilateral agreements and, the freedoms beyond the fifth, have not been officially recognized by international treaty (Hamilton, 2007). According to Milde, as of 2008, 67 of the participating ICAO states have not agreed to the International Air Services Transit Agreement, meaning they only agree to the first two freedoms. While the states may support having the international system in place to aid the overall growth of the aviation industry, there are many states that do not participate fully in the system. State sovereignty is a very important issue to individual states: if a smaller state allows another entity to have authority over it then there is a chance that the smaller state will lose its voice in the international system to larger and more powerful 
states. The goal is to find the balance between progress and improvement in the system and keeping individual states satisfied.

\subsection{International Objectives}

ICAO has listed its specific objectives as derived from the Chicago Convention. These objectives include:

a. Promoting the safe and orderly growth of civil aviation throughout the world.

b. Fostering the technical arts of aircraft design and operation for peaceful purposes.

c. Encouraging the development of airways, airports, and air navigation facilities for international civil aviation.

d. Meeting the needs of the world's people for safe, regular, efficient, and economical air transportation.

e. Preventing economic waste caused by unreasonable competition.

f. Ensuring the rights of contracting states are fully respected and that every contracting state has an equal opportunity to operate international airlines.

g. Avoiding discrimination among contracting states.

h. Promoting the activities of all aspects of international civil aeronautics (FAA, 1994).

ICAO has expanded the stated objectives through its published standards known as "annexes." There are currently 18 annexes that describe how ICAO believes states should handle issues from flight crews to security at airports (ICAO, n.d.). Along with providing procedures through annexes, ICAO also publishes other reports that deal with 
safety issues in aviation. One of these reports is titled the "State of Global Aviation Safety" (ICAO, 2011). This report contains statistics and information about the current aviation industry from a global perspective and details particular items such as accident rates and training procedures (ICAO, 2011).

A program that specifically focuses on member states maintaining compliance with international standards as outlined by the annexes is the ICAO Universal Safety Oversight Audit Programme (USOAP). This audit identifies areas of non-compliance where resulting changes if implemented will help states to correct the deficiencies. There are four components that such audits use to assess compliance for the USOAP: the overall aviation related activity in an individual state, the level of compliance to the safety related international standards, the percentage of the compliance of the State's regulations to ICAO standards, and the challenges the states face to improving their safety programs (ICAO, 2011). It should be noted that two of these areas focus specifically on safety. According to ICAO, in 2010, 177 of the 190 member states, constituting 99 percent of the world's air traffic, had been audited under the program (ICAO, 2011).

Three of the nine international objectives listed directly use the word "safe" to describe the goal and at least three of the others imply that safety is required in order to complete the objective. The emphasis on safety in the objectives indicates that it is a key element to a successful aviation industry. When an aviation accident occurs anywhere in the world, especially involving injuries or fatalities, the general public is informed almost immediately that the accident has occurred. In June of 2012 a plane crashed in Nigeria that killed 153 people. That same day, CBS News in the United States had already 
compiled a report on the crash and was releasing details to the public (CBS News, 2012). A plane crash, especially one where people are killed, perpetuates the fear that causes people to resist or to refrain from flying (USA Today, n.d.) An airplane incident usually becomes a high profile event because of the large number of people involved. In order to maintain a positive image with the general public, the aviation industry must become an industry where accidents are few and fatalities are at a minimum.

\subsection{ICAO, Best Option for Global Safety}

In the globalized, interconnected world of today, where the latest news is reported almost instantly, the perception of safety in the aviation industry is just as critical to its success as the actual safety rating. The extent to which states support and comply with international standards directly affects actual safety, and ultimately the public's perception of safety. Any accident involving a commercial airline garners attention because of the number of possible fatalities and the enormous financial implications usually associated with it.

In 1992, the FAA did an investigation into ICAO compliance of standards by other states and found that, while there are not any states with 100 percent compliance, two-thirds of the 32 states reviewed substantially failed to meet ICAO standards, and thus were not allowed to fly into the United States with their own aircraft (Abeyratne, 1998). This indicates a commitment by states such as the United States to abiding by and enforcing the ICAO standards agreed upon. In 2011, the European Union (EU) used ICAO standardization to restrict certain states' airlines from flying into the EU. This ban involves states such as Afghanistan, Republic of Congo, and Liberia where internal 
turmoil makes it difficult to comply with international standards and safety records are not good (Europa, 2011). These bans, while maintaining a safer industry for certain parts of the world, are not effective in improving the overall safety of the world. Kent Gourdin (1998) states, “Unfortunately, air service agreements are negotiated just like treaties, which means that other national issues unrelated to aviation can often influence the final outcome" (p. 18). This is important because it demonstrates a significant weakness in the international system when individual state sovereignty is held at a premium. Ultimately ICAO has a significant lack of authority to enforce its own policies. It relies on the assumption that the individual states will do everything they can to maintain the system the way it is designed.

The principles and guidelines established by ICAO that set the basis for how states should frame their own regulations are known as the Standards and Recommended Procedures (SARPs). According to Button, Clarke, Palubinskas, Stough and Thibault (2004), "These cover an entire gamut of subjects ranging from licensing of airmen to the shipment of dangerous cargoes" (p. 253). These standards are promulgated throughout the industry in order to establish a basic level of safety and uniformity among the member states (Wells \& Rodrigues, 2004). The ability to which the member states are able to apply these standards in their own aviation legislation is the basis for the USOAP audit and determining the Effective Implementation percentage. According to Button, Clarke, Palubinsaks, Stough, and Thibault (2004), “The overall principles of safety oversight requirements, that apply to national governments, were laid in the Convention Treaty but have been refined, and effectively operationalized" (p.253). 
In order for ICAO to operate effectively, compliance to standards is only one step. It is important for member states to contribute financially as well as with other available resources. The United States is one of only a few major monetary contributors that keep ICAO working as it was intended. According to the 2011 State of Global Aviation Safety Report by ICAO, the Republic of Korea donated $\$ 51,000$ USD since 2006 to help improve safety programs of ICAO member states. On the other hand, the Millennium Challenge Corporation, an agency of the United States government, is providing an airport in Mali \$183,000,000 USD to improve the Bamako-Sénou International Airport as well as civil aviation safety and airport management. Many states do not provide monetary contributions to ICAO to improve aviation; however, money is not the only means to support ICAO. Credited as a significant accomplishment by ICAO, Japan sent 15 aviation experts to different states in Southeast Asia to provide assistance to improve air traffic control and navigation facilities (ICAO, 2011).

Aviation is a major global industry, as people and cargo travel around the world by airplane on a daily basis. On international flights, aircraft are operated between states thus requiring significant cooperation. ICAO is the foundation that has helped that process. What began as a new organization with relatively few participating states is now a large IGO involving almost every country in the world. Ultimately having an accident free, cost efficient aviation industry is the most desirable goal, and states are continuously negotiating, compromising and trading in an effort to achieve that. States that participate in the international system have a guaranteed way of being able to voice their opinion and engage in multilateral discussion to improve the global safety of aviation. 


\subsection{Aviation Safety Trends}

Accidents and incidents are counted and analyzed through investigations and written reports. According to Wells and Rodrigues (2004), "the accident and its investigation remain the most conspicuous source of insights and information leading to accident prevention" (p.73). Incidents, or "events that can be defined loosely as nearaccidents" must be reported by an individual involved in the incident in order for information to be accumulated (Wells \& Rodrigues, 2004, p. 74). The term incident is defined under Title 49 CFR Part 830 of the United States Code of Federal Regulations as, "an occurrence other than an accident, associated with the operation of an aircraft, which affects or could affect he safety of operations" (U.S. DoT, 2012, p. 491). There are many databases that are used to collect information on accidents and incidents. The United States has four organizations that collect and store data. These are the National Transportation Safety Board, Department of Transportation, National Aeronautics and Space Administration and the Federal Aviation Administration (Wells \& Rodrigues, 2004). There are also international databases that store information on accidents and incidents. There are ICAO's Accident/Incident Reporting System (ADREP), the Aircraft Accident Digest, and the List of Final Reports Available from Countries (Wells \& Rodrigues, 2004). These systems require an exchange of information that necessitates the cooperation of states and a willingness to share data. As Wells and Rodrigues note, "most of these countries use compatible EDP formats and codes, making it possible to exchange data tapes and thus benefit from each other's experience" (p. 90). Not all states use this format and many states, such as the United States, have their own reporting systems and organizations dedicated to accident and incident investigations. 
Accident trends vary among regions as well. According to the ICAO Safety Report (2012), "the number of accidents grew by 4.1 percent and the global accident rate for 2011 remains unchanged at approximately 4 accidents per million of departures" (p. 5). The number of accidents varies by regions, as well, with 10 percent of accidents in Europe resulting in fatalities and 26 percent in Latin America and the Caribbean. North America and Oceania had among the lowest number of fatal accidents (ICAO, 2012). The ICAO Safety Report (2012) also states, "the considerable variance in traffic volume among regions is a factor which needs to be considered when drawing broader conclusions from accident rate information" (p. 11). In general, the more traffic that a particular region has, the more accidents can be expected. North America, with the most commercial traffic, despite having the highest number of accidents, did not have a single fatality in 2011 (ICAO, 2012). It is also important to note that the ICAO Safety Report (2012) also states, "the growth in volume in commercial scheduled flights seen in 2010 continued in 2011 at a rate of 3.5 percent. This increase coincides with a 3.7 percent increase in the global real Gross Domestic Product (GDP)" (p. 5).

\subsection{Chapter Summary}

This chapter reviews the existing literature on ICAO standards and implementation effectiveness in detail and provides a framework and historical context for the research that will be completed. The next chapter describes the methodology that was used to complete the research. 


\section{CHAPTER 3. METHODOLOGY}

This section outlines the type of research that was performed, how the study was conducted, and how the data was analyzed.

\subsection{Research Type and Framework}

This thesis is a quantitative research study to test if a relationship exists between compliance rate of an individual state to ICAO standards and number of fatalities in commercial accidents between 2005 and 2012. This research uses a correlation model that tests the results against a null hypothesis determined by the evidence of a relationship. The key independent variable in this study is the Effective Implementation percentage of each individual state as given by ICAO. This implementation rate is determined from an average of percentages obtained from eight key ICAO areas, "The Eight Areas Audited for Effective State Safety Oversight” (ICAO, 2011, p. 7).

According to the 2011 ICAO State of Global Aviation Safety Report, these areas include:

1. Primary aviation legislation and civil aviation regulations

2. Civil aviation organization

3. Personnel licensing and training

4. Aircraft Operations

5. Airworthiness of Aircraft 


\section{Air navigation services}

7. Aerodromes

8. Aircraft accident and incident investigation (p. 7)

ICAO has a list of specific questions in each emphasis area, called protocol questions. The total number of questions determined to be satisfactory divided by the total number of total protocol questions for a particular area is calculated to be an implementation rate. ICAO audits the regulations of each member state and associates the regulations with the emphasis areas. A protocol question in an emphasis area is determined to be satisfactory by a state when compliance answers the question. Each emphasis area has an overall compliance rate based on the compliance of regulations in that particular area. The average of the eight implementation rates is calculated, determining the Effective Implementation rate for a particular state (ICAO, 2010a).

The key dependent variable is fatality rate, determined by creating a ratio of fatalities per departure. This eliminates bias that results from a state with a significantly larger aviation industry and a larger fatality rate. Once a correlation value is determined it can then be tested against a null hypothesis. The research question is as follows:

-What is the correlation coefficient between ICAO Effective Implementation percentage and accident fatality rate, determined at a .05 alpha level of significance.

For this study, a negative correlation meant an increase in Effective Implementation was linked to a decrease in fatality rate. A positive correlation (an increase in compliance standards correlating to an increase in fatalities) fails to show that compliance to standards is an effective way of reducing fatality rates or increasing safety. 


\section{$3.2 \underline{\text { Sample }}$}

The sample being used in this research is the set of data from reporting member states of ICAO. There are 191 participating states in ICAO, but only 179 states have reported their implementation percentage to ICAO between 2005 and 2012. From that list of 179, there are two states, San Marino and Andorra, which do not have any reported commercial departures or fatalities, and were excluded. Therefore, 177 of the 191 member states meet the requirements for this study. A random sample does not need to be taken to draw conclusions about the entire population because enough data is available and nearly every state in the overall population has reported data.

\subsection{Data Collection}

The data used in this study was collected by ICAO. Of the 191 participating states in ICAO, Effective Implementation rates were only collected from 179 between 2005 and 2012. Their data also contains the number of fatalities that occurred during that period along with the number of departures. The number of fatalities was divided by the number of departures to determine a fatality rate for a particular state. Bowen and $\mathrm{Lu}$ (2004) determined in the Aviation Safety Rating that the three most critical factors to evaluating safety were fatality rate, average fleet age and accident rate. This will be the key data used to determine if a relationship exists for the purpose of this study.

Inequality of wealth is evident around the world, with the states divided into categories of developed states, developing states and underdeveloped states. According to Tucker's Inequality Among Nations (1977): 
It is the conditions of a society marked by the absence of effective collective procedures, competitive rather than cooperative, and lacking in commitment to a common good that has insured the differences in power and wealth will be employed to perpetuate inequality (p. 3).

These inequalities result in an uneven continuum of development (Tucker, 1977). These differences in wealth equate to varying amounts of money available for states to spend, and less wealthy states inevitably cannot afford to spend the same amount of money on the same matters as wealthy states. A common figure used to determine the wealth of a state is the Gross Domestic Product (GDP). GDP has been used as a covariate in previous studies, such as a correlation study by Goldhaber-Fiebert, Lipsitch, Mahal, Zaslavsky, and Salomon (2010) concerning death rate and measles vaccinations in 44 countries. This study found that higher levels of vaccine coverage reduced the mortality rate in measles-related deaths in children under five. It also found that states with less GDP values benefit more from higher vaccine coverage than states with higher GDP values (Goldhaber-Fiebert, et al., 2010). Just as there are inequalities among states in healthcare, there are inequalities among states in aviation system expenditures. These inequalities of wealth make it difficult for states to maintain a safe aviation industry and thus GDP can be used as a covariate to control for this. The GDP numbers in this study were obtained from the World Bank database between 2005 and 2012.

\subsection{Testing Method}

The Pearson Product Moment correlation was used to identify the relationship between compliance rate and fatality rate. SPSS was the statistical tool used to evaluate 
the data and to run various correlations and models. A datasheet in Microsoft Excel contained the original values and categories used as input into SPSS. An r-value was determined in the range from -1 to 1 with a negative score determining if a correlation exists for the purpose of this research. The GDP was used to control for variations in wealth of the member states. To account for this variance, an analysis of variance (ANOVA) was performed with GDP as a covariate. The GDP numbers for each state were averaged between the years 2005 and 2012 in order to accurately compare them to the average ICAO data over the same time period.

The data collected and the tests that were performed were verified as both reliable and valid. Reliability and Validity refer to the ability for the outcome to be consistent and accurate. Sproull (1995) defines reliability as "consistency for measurement. The degree to which an instrument measures the same way each time it is used under the same conditions with the same subjects" (p. 74). The data was obtained from a test conducted and verified by ICAO. The Pearson correlation and ANOVA are common statistical tools used for analysis (Warren, 2013). They are used repeatedly and are known for producing consistent results.

Validity, as defined by Sproull, is "accuracy of measurement. The degree to which an instrument measures that which is supposed to be measured" (p. 74). The USOAP by ICAO was established to measure Effective Implementation percentage. The fatality number counts those where the fatality occurred, not necessarily the state where the flight was registered. The Pearson correlation and ANOVA tests are widely used tools in statistics that analyze the information accurately as well. New tests were neither 
designed nor implemented in this study, thus reliability and validity have already been established for the tools being used for analysis.

\subsection{Chapter Summary}

This chapter describes the important variables used in the research, and the hypotheses that need to be tested. It also describes the data used and the testing methods utilized. 


\section{CHAPTER 4. DATA AND FINDINGS}

This chapter describes the quantitative analysis and findings from the dataset containing Effective Implementation rate of ICAO member states and their associated fatalities between 2005 and 2012 .

\subsection{Data Analysis}

The following analysis examines the relationship between a member state's compliance with international aviation standards and the number of fatalities that occurred. It takes into account various factors such as region of the globe, economic development and average gross domestic product (GDP) to illustrate how these factors moderate the relationship between states, state compliance, fatalities, and fatality rate. The data were analyzed to answer the research question presented, determining specifically the extent of the relationship between Effective Implementation and fatality rate. Table 4.1 is an abbreviated section of the complete dataset used for analysis; however, the entire dataset can be found in Appendix A. There were a total of 177 member states that had enough data to be able to make an appropriate analysis. From the 191 original states in the data set, 11 did not yet have an implementation analysis percentage completed through the Universal Safety Oversight Audit Programme (USOAP) by ICAO. From the 179 states that did have a percentage, two more states, San 
Marino and Andorra, were removed from analysis because they did not have any reported commercial aircraft departures over the specified time period of this study. This analysis specifically focused on states with a functioning commercial system with the possibility for fatalities, so the removal of these two states was necessary and appropriate.

Table 4.1 Excel ICAO Member State Data Sample

\begin{tabular}{|c|c|c|c|c|c|c|c|c|c|c|}
\hline SSatus & 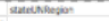 & Sativare & 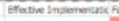 & & 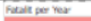 & & aspinas & 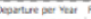 & Fienty be bepents & AVG GDP \\
\hline ideveroped & d Noroven Averica & 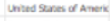 & 2019: & siseneos & & 162 & 210,9s,רen & 15994723.5 & 1.0143E-06 & $1.4129 E+13$ \\
\hline developed & d sampe & Resien fodervion & 50.50 & s.1.2000 & & 138 & 4usiess & 520129.375 & 0,00023436 & 1.4739E+12 \\
\hline develoged & dase & are & 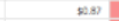 & $8: 600$ & & $n$ & 22.468468 & 2910552 & 273960.05 & $5.45 C 6 E+12$ \\
\hline ideveloped & d Lon hatera aed De & (saal & 50.96 & 55600 & & 62 & sostent & 1013076.13 & 66135E.06 & $1.6992 E+12$ \\
\hline developed & $d$ Gerpet & farce & 525 & $5 \sin 200$ & & 6s & gaxus & 114104.75 & $73228 E-06$ & $25001 E+12$ \\
\hline devoloping & & Nageria & 2.2 .4 & nesos $\infty$ & & 64 & 258270 & 69213.75 & 0,00087772 & 2.153E+11! \\
\hline developed & & 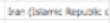 & 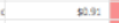 & 50000 & & sin & Lasase & 143767.875 & 0.00040864 & $4.1479 E+11$ ! \\
\hline developing & & insenewa & 50,3 & noton & & st & 295927 & 494734 & 0.00011622 & $6.1242 E+11 \mid$ \\
\hline ideveloping & & $\operatorname{ten} a$ & soss & semos & & * & Gisuss & 76960.875 & 0.00062131 & 3.3927E+10! \\
\hline deveioping & & now & 50.2 & $n \geq \infty$ & & 3 & SSESSes & 693322875 & $490395-06$ & 1.7343E+12; \\
\hline ideveioped & d Len kneza and one & robomba & 50.90 & seces & & 33 & $20 m, 121$ & 312390.125 & 0.00010564 & $26036 E+11 !$ \\
\hline developing & g then & 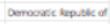 & 50.13 & $5 \times 000$ & & 표 & 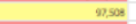 & 12188.5 & 0.00266645 & $1.315 E * 10^{\prime}$ \\
\hline developing & & Nexex & 5284 & 22600 & & za & $x=00$ & 95363.75 & 000029617 & $20091 E+11$ \\
\hline develoging & gxtoca & $\sin$ & 52.00 & $m \infty$ & & 28 & Dos:en & 21371.125 & 0.00130433 & $52835 E+101$ \\
\hline developing & 9 turpet & wrave & 50.75 & maxom & & 27 & $\cos , 26$ & $n, n_{2}$ & 0.00003502 & $1.6002 E+11$ \\
\hline developed & denpe & $\operatorname{sen}$ & 5285 & $\sin 100$ & & 24 & 20stix & 1133141.13 & 210695.06 & $1.3902 E+12$ \\
\hline developing & 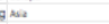 & rrostan & 500 & sineos & & 24 & $x, 203$ & 9662875 & 0.00224562 & 5380696400 \\
\hline developing & & Ancpes & 506: & $\operatorname{sis} 20$ & & $x$ & ses:ns & 225214875 & 90469E.06 & $1.947 E \cdot 11$ \\
\hline developing & 9 Nowa & Gove & 5292 & nexos & & $x$ & $232=20$ & 102890 & 0.00019803 & $20021 E+11$ \\
\hline developing & & $-x$ & $=2.2$ & sissoo & & 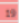 & $m, 00$ & 55624.625 & 0,00006832 & $1.6043 E+10$ \\
\hline deveroped & & onar & 5053 & seos & & is & $2 m, 105$ & 36120.625 & 0,00062387 & $5 ., 6687 E+10$ \\
\hline developed & & Tuser & 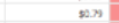 & seevos & & is & 2.02 .38 & 270296.125 & $65668 E-05$ & $7.0663 E+11$ \\
\hline developed & d Norem Averia & areata & 53.96 & 13200 & & p & $2.21 \mathrm{~s}>\mathrm{pt}$ & 154071263 & 1.07095 .06 & 1.4296E +12 \\
\hline deveroping & 9 Ntha & cones & 5023 & 51000 & & 36 & ss, sete & 10706.125 & 0.0014828 & 1.1171E +10 \\
\hline deveroped & diensen & 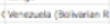 & nass & w & & 15 & 200.:37 & 179146375 & 85t25E-06 & 2.996E*11 \\
\hline developed & & arens & EsAn & $\vec{w}$ & & is & $20,7: 9$ & 36699.875 & 0.00041056 & $22191 E+10$ \\
\hline deveroped & Sumpe & Sneses: & 5278 & 13 & & 15 & 282,036 & 352754.5 & $4.1813 E-06$ & 4.4031E+11 \\
\hline deveroping & & Arema & $x=5$ & in & & 3 & $\operatorname{sens}$ & 10513.875 & 0.001343468 & 9921271185 \\
\hline developed & A Aloce & 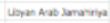 & 32845 & sat & & u & 20,000 & 28800 & 0.00044581 & $6.4844 E+10$ \\
\hline developed & 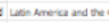 & iscousos & $5: 260$ & $n$ & & 12 & sDoal & 67126.625 & 0.00018635 & $6.1126 E+10$ \\
\hline develobed & d ana & nuvere & neas & 2 & & 22 & 20 asto & 297968575 & 39932E. - 66 & $30967 E+11$ \\
\hline developed & 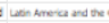 & (t)e- & $\cos 25 \mathrm{~s}^{-1}$ & $n$ & & : & mates & 99607375 & 0.00011536 & $1,4 B E 2 E+11]$ \\
\hline developing & G Alow & Exiose & 6ec2s & $x$ & & "I & 20,200 & 36291.125 & 0.00030999 & $32606 E+10$ \\
\hline developed & d whe & soset retera & mStM & " & & it & $2 . \operatorname{men} 25 s$ & 273531.875 & $40671 E .06$ & $33788 E+11$ \\
\hline developed & d Len wereza and the & ratas & sonst & a & & 3 & 256,26 & 31828 & 0.00033036 & $5.8288 E+10$ \\
\hline developed & dase & Sroverese & 9AA:S & a & & $: 8$ & Dastew & 157675.375 & 6.57996 .05 & $19477 E+11$ \\
\hline developing & g teso & 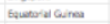 & $2 \mathrm{am}$ & $n$ & & 3 & $0,2,25$ & $3.783,125$ & 0.00002372 & $1.542 E+10$ \\
\hline ideveioped & dase & satros & 56035 & $n$ & & 9 & $3 \times 5,22$ & 48178.375 & $0.00018<21$ & $2.1278 E+101$ \\
\hline deveioped & G Guspe & 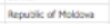 & so.25s & $x$ & & ; & $2,2,20$ & 7865.875 & 0.0011124 & 5959162362 \\
\hline deveroped & $8 \cos$ ant & cNenes & nexas & a & & . & 612,78 & 765216.5 & $1.0291 E-06$ & $1.094 \pi E+12$ \\
\hline developing & $g$ ase & $\cos x$ & 32895 & जे & & 7 & $65>33$ & 8217.875 & 0.00069743 & $1254 E=10$ \\
\hline deveroped & furpe & sonemented & $82 \pi 0$ & जै & & 7 & $25 \sin 34$ & 31746279.25 & $22442 E-06$ & $4 B 102 E+11$ \\
\hline developing & 9 ocania & 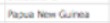 & ans: & ज & & , & $65:, 66:$ & 81420.125 & $875096-06$ & 9202721706! \\
\hline deverioging & & vestumen & 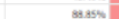 & 52 & & $;$ & $2 m$ & 3612425 & 000019048 & $37872 E+10$ \\
\hline
\end{tabular}

The states that did not have identified implementation percentages were states with small commercial aviation operations, the largest of which had an average of 66,233 departures a year and the smallest only had 373 departures a year. There are 274,806 average departures per year among the 177 member states used in the study. A complete list of the member states not examined in this analysis can be found in Appendix B. 
The remaining 177 member states used for analysis still represented every region of the globe consisting of 97.2 percent of total commercial fatalities between 2005 and 2012, as well as 99.7 percent of global commercial departures in that same period. With nearly all of the global aviation industry accounted for, an understanding of compliance to international standards and its relationship to fatalities can be evaluated.

One of the most problematic issues facing the analysis was the difference in size of operations. The variability and range of numbers appeared to skew the data and interfere with its linearity. The largest state with the most departures over the eight-year period was the United States of America with 127,957,788 departures. The smallest state evaluated was Nauru with a total of 2,209 departures. The total number of fatalities also appeared to skew the data with the United States of America having 1,298 fatalities, the largest number of fatalities over the specified time period. Nauru, in comparison, did not have a single fatality along with 67 other states. As shown in Figure 4.1, a simple linear regression appears to indicate that an increase in departures correlates to an increase in fatality rate. The Pearson correlation statistic determined there to be a correlation of .654 , and an $r^{2}$ effect size (ES) of .428 . The $r^{2}$ of .428 means that 42 percent of the variation of fatalities is explained by departure size. Cohen (1988) created a scale for ES for $r$ and $r^{2}$ values, establishing .1 or .01 and below as a weak ES, between .1 or .09 a medium ES, and .5 or .25 and above as a strong ES. Cohen stated, "My intent was that medium ES represent an effect likely to be visible to the naked eye of the careful observer" (p. 156). This indicates that there is a noticeable increase in fatalities as the size of commercial operation within a state grows. In order to account for this disparity, it is more appropriate to use metrics that control for the size of the operation. In order to 
do this, the average fatalities per year were divided into the average departures per year, as determined from the eight-year scope.

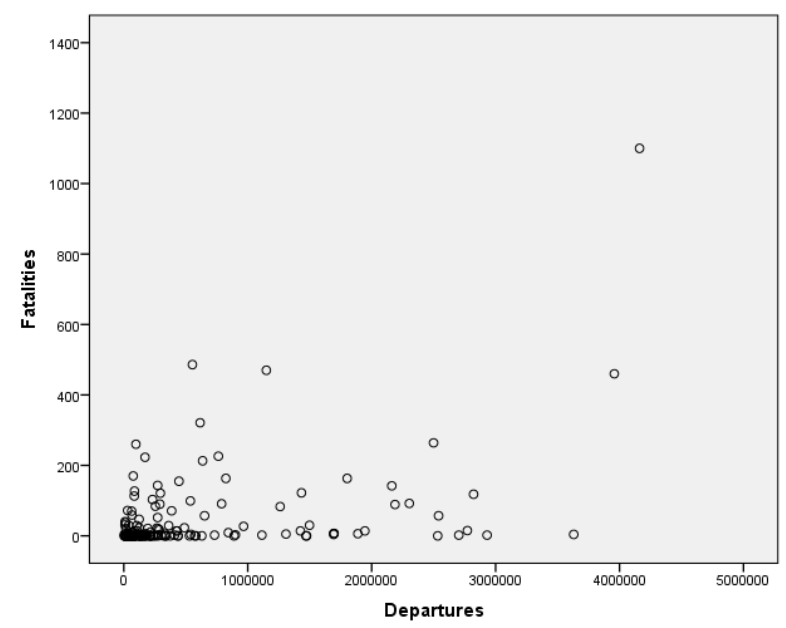

Figure 4.1 Scatter Plot of Total Departures and Total Fatalities Between States

This information (see appendix A) was obtained from the column in the original dataset titled "Fatality per Departure". This adjusted measure accommodated for the different sizes of operations in each state. By accounting for the size of the overall commercial operation in a state, the comparison of Effective Implementation percentage to fatalities was more plausible. Figure 4.2 shows the scatter plot of all states with the Effective Implementation being compared to the average fatality per departure, or fatality rate. The basic Pearson correlation coefficient for this analysis is -.236 and a corresponding $r^{2}$ of 056. This is not a strong effect size, but almost six percent of the variation of fatalities is explained by Effective Implementation. This suggests that as Effective Implementation increases (as states become more compliant with international standards) the overall 
fatality rate per departure decreases. An analysis of variance (ANOVA) was conducted for this regression as well. The null hypothesis tested if the slope of the predictor, Effective Implementation, is equal to zero. In this analysis the $F$ statistic was 10.278 corresponding to a p-value of .002, significant at the .05 alpha level.

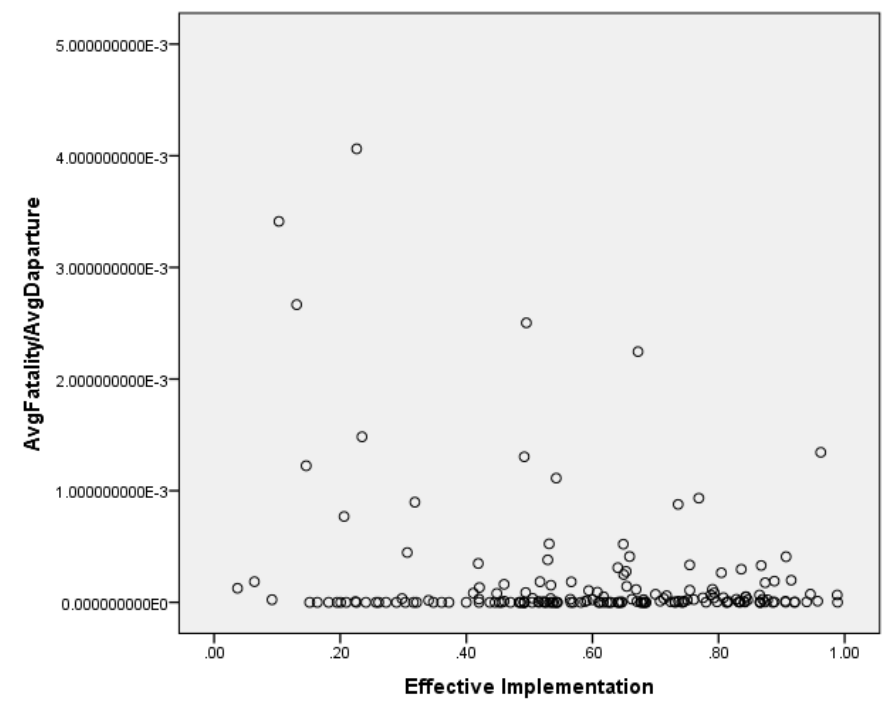

Figure 4.2 Scatter plot Comparing Effective Implementation Rate and Fatality per Departure

\subsection{Regional Variance}

The world has multiple regions and each has a unique set of characteristics.

These regions have different levels of overall growth, different sized aviation operations 
as well as different fatality rates. ICAO has a framework for combining the member states into 6 different regions: Africa, Asia, Europe, Latin America and the Caribbean, North America, and Oceania. Figure 4.3 shows the total number of member states within each region. It is important to note that the regions have differing numbers of states. Africa, Asia and Europe have the most states within a region, while Oceania and North America have the fewest. An examination of Figures 4.4 and 4.5 reveals that the number of commercial departures and the total number of fatalities do not correspond to the number of states: in both figures, North America has far more of both fatalities and departures than the rest of the regions of the world.

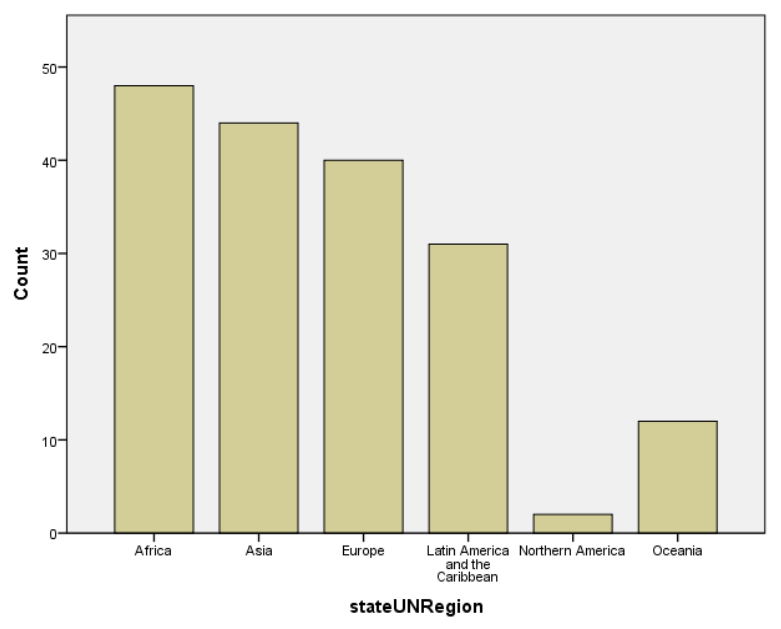

Figure 4.3 Number of ICAO Member States in Each Region 


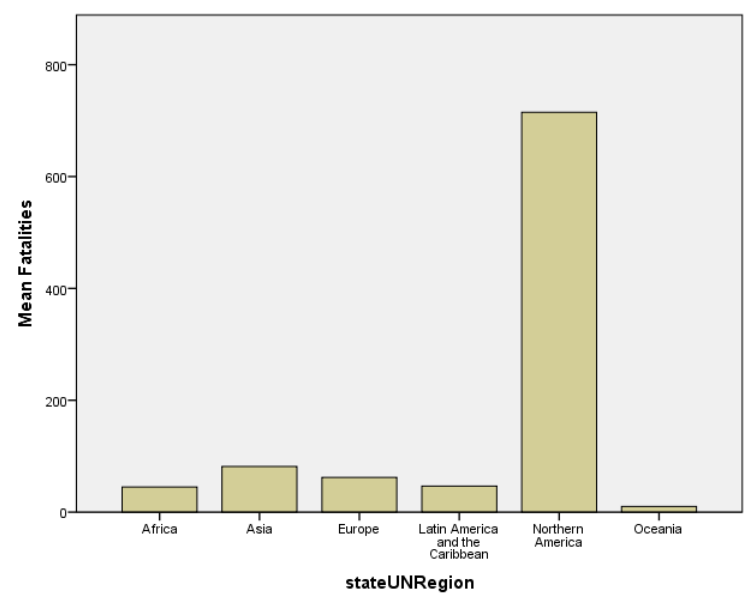

Figure 4.4 Average Number of Fatalities per Region

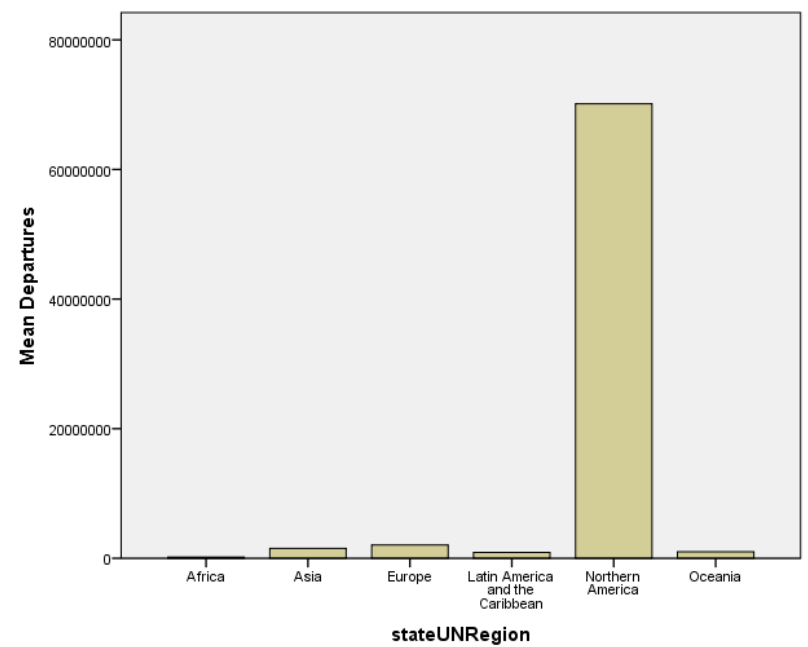

Figure 4.5 Average Commercial Departures by Region

It is not possible to statistically compare the means of the regions with ANOVA because the groups did not exhibit equal variance, which is a fundamental assumption of 
ANOVA. Levine's test for homogeneity is a statistical tool able to determine if constant variance is violated. A p-value less than .05 is significant and significance in this test indicates that the assumption is not met and the ANOVA cannot be performed. Testing the variance between regions on variables including departures, fatalities and Effective Implementation, significant results were returned. The critical value of the test for homogeneity was 5.316, corresponding to a p-value of less than .001. Because the difference between the means is significant the ANOVA cannot be performed to compare regions. The bar graphs of Figures $4.3,4.4$, and 4.5 provide a graphic representation of these discrepancies.

\subsection{Covariate Analysis}

As seen in earlier figures, there is a wide variance of the number of states in each region and the number of departures. The United States of America, for example, is one of only two states representing the North American Region (Mexico is included in the Latin American and Caribbean states in this analysis), yet this region ranks the highest in departures and fatalities, from 2005 through 2012. Data derived from the World Bank and the Central Intelligence Agency (CIA) and averaged over the same time period shows that the amount of money available to a state in terms of Gross Domestic Product (GDP) also varies widely. Table 4.2 shows an abbreviated list of the variance of GDP by state. As seen in the table, the United Kingdom of Great Britain has maintained an average GDP of about $\$ 2.4$ trillion USD between 2005 and 2012, while a state such as Vanuatu in the Oceanic region has only averaged \$652 million USD over that same period. This table represents a small sample of the disparity of GDP between states as 
well as the regions of the world. As the entire GDP represents the accumulated wealth of a state, and that state spends its money on a variety of factors, there does appear to be a correlation between GDP and the Effective Implementation rate based on an r value of .3 and as shown in figure 4.6. The outlier in the top right corner is the United States. The United States has the largest average GDP from 2005 through 2012 with about \$14 trillion USD. The United States has a high implementation

Figure 4.6 Scatter plot of Effective Implementation Rate and Average GDP

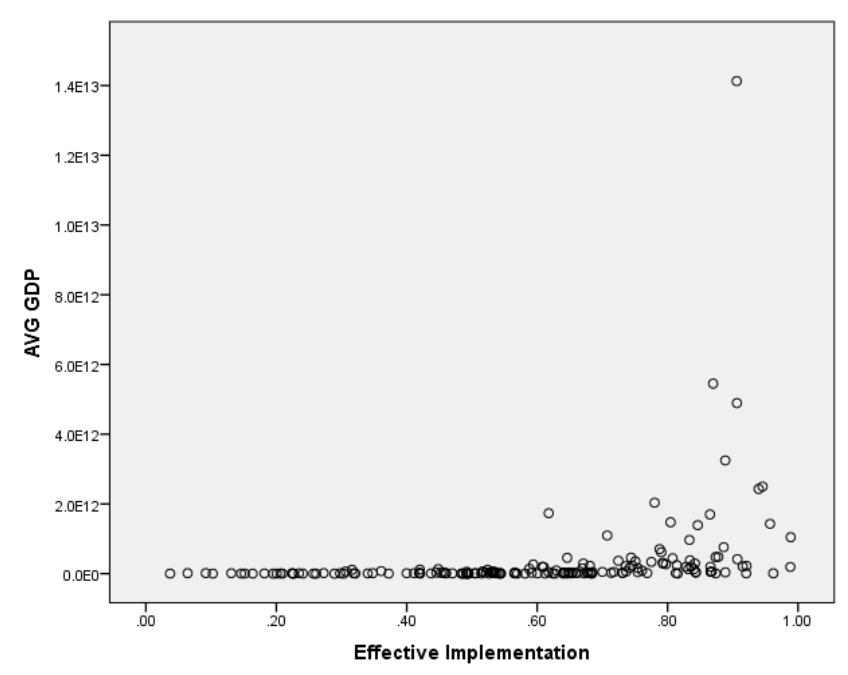

Table 4.2 State Name and Economic Status

$\begin{array}{cccc}\text { Status } & \text { Region } & \text { State Name } & \text { Avg GDP \$US } \\ \text { developing } & \text { Africa } & \text { Zimbabwe } & 6379000000 \\ \text { developed } & \text { Latin America } & \text { Venezuela } & 289595000000 \\ \text { developing } & \text { Oceania } & \text { Vanuatu } & 652000000 \\ \text { developed } & \text { Europe } & \text { United Kingdom of } & \\ & & \text { Great Britain } & \\ & \text { Asia } & \text { Turkmenistan } & 21036980000000 \\ \text { developed } & & & \end{array}$


percentage, around 91 percent. South Korea has the highest implementation percentage, almost 99 percent, but only has around an average GDP of $\$ 1$ trillion USD. The scatter plot suggests that an increase in Effective Implementation corresponds to an increase in GDP. The Pearson correlation between the two variables was .30, and had a corresponding ES of .09: as Effective Implementation increases, GDP does as well. Nine percent of the variation in Effective Implementation is explained by GDP. Until an implementation rate of around 60 percent is reached the correlation is not very evident to the eye. A scatter plot examining the correlation between the developed states and developing states as defined by the United Nations Statistics Division is presented in Figure 4.7. The states were classified as economically developing states or developed states, based on the United Nations Statistical Division, to determine if the economically weaker states are those that constitute a horizontal line across the bottom of the graph, or, if as they improve economically, their ability to comply with the international standards increases accordingly. SPSS was used to draw a regression line, or line of best fit, for both the developing sates and the developed states. These regression lines attempt to predict a particular point for a given unit across the x-axis. Warner (2013) states, "the nature of the relation between $\mathrm{X}$ and $\mathrm{Y}$ is describe by the slope coefficient, $\mathrm{b}$, which can be interpreted as the number of units of change in the raw score on $\mathrm{Y}$ that is predicted for a one-unit increase in the raw score on X" (p. 344). This means that on the regression line a value is constructed that determines the rate at which the line increases or decreases per unit. A line that increases as $\mathrm{x}$ increases has a positive slope, while a line that 
decreases while $\mathrm{x}$ increases has a negative slope. In Figure 4.7, the regression line for each group was determined by SPSS calculations. There is a positive slope for both regression lines, but there is a difference between the slopes of developed and developing states comparing Effective Implementation on the x-axis and Average GDP on the y-axis; the developing states have a slope of .045 and the developed states having a slope of .11. Because there is a positive correlation between GDP and Effective Implementation percentage, among both developed and developing states, after accounting for GDP, a relationship between Effective Implementation and fatalities exists.

As previously described, using the measurement of average fatality per departure minimizes the disparity between total number of fatalities among states. It cannot eliminate the disparity, however, because there are other factors that contribute to the total number of fatalities such as the size of aircraft. Larger aircraft carry more people; one crash may have 150 fatalities for just one departure. Certain states may have more accidents; yet, because of smaller aircraft, they may not have as many fatalities. The size of operation within a state may also affect the average fatality per departure as well. States with a large aviation system, such as the United States, have a larger sample size to reflect the number of fatalities. To account for this, using average fatalities per departure as a variable reduces the chance for misinterpretation and standardizes the dataset. The variation in number of departures among region is important and necessary to consider when evaluating accident rates, as noted by the ICAO Safety Report (ICAO, 2012). Using the average fatality per departure as a variable, an ANOVA test was performed to conclude the significance of Effective Implementation after accounting for GDP. The analysis conducted showed a partial correlation of -.224. This partial correlation 
explained the relationship between Effective Implementation and average fatality per departure after GDP was already taken into account in the statistical model. A t-test showed that these results had a critical value of -3.037 and a p-value of .003 . The negative correlation indicates that as Effective

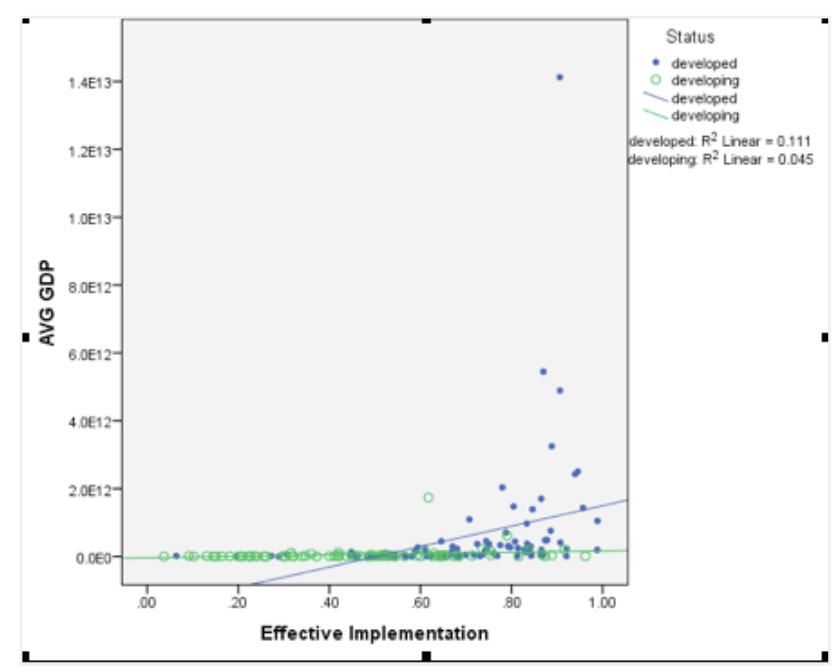

Figure 4.7 Effective Implementation Rate Compared to Average GDP by Economic Status

Implementation increases, the number of fatalities per departure decreases. The p-value indicates that even with a relatively low slope for the developing states, as indicated at the lower end of the scatter plot in Figure 4.7, there is still enough data to show an effect. 


\section{CHAPTER 5. CONCLUSIONS AND RECOMMENDATIONS}

This chapter discusses the conclusions derived from the analysis of the data in the previous chapter. For the purpose of drawing conclusions in this study an alpha level of .05 was used to determine significance. This is a common number used in statistical quantitative research. Meyers, Gamst, and Gaurino (2009) described it as the "traditional 0.05 level" (p.34), implying there is only a five percent chance that the null hypothesis will be falsely rejected due randomness of the data collected. This research included an analysis of several correlations. The Pearson correlation was used to determine the $r$ value and $r^{2}$ value, and values of $.1, .3$, and .5 , or $.01, .09, .25$, and can be considered small, medium and large correlations respectively (Cohen, 1988).

\subsection{Conclusions}

There are several conclusions that can be drawn from the analysis of the data. Based on the overall analysis of Effective Implementation and average fatality per average departure, a relationship is suggested. The Pearson correlation $r$ value of -.23 between the fatality rate and Effective Implementation is negative, meaning that as Effective Implementation increases, the fatality rate decreases. The 67 states that had no fatalities during the sample period do not prevent a relationship from existing, even 
though not a single state in the upper ten percent of implementation percentages was fatality free.

The scatter plot showing the relationship between Effective Implementation and GDP also indicates a correlation. The $r$ value obtained from that analysis, .30 , is a positive correlation and slightly stronger than the relationship between implementation and fatality rate. The positive correlation suggests that as GDP increases, implementation increases as well. However, the scatter plot indicates that there does not appear to be a meaningful rise in GDP as implementation increases until an implementation percentage of approximately 60 percent is reached. As stated by the ICAO Safety Report (2012), "the growth in volume in commercial scheduled flights seen in 2010 continued in 2011 at a rate of 3.5 percent. This increase coincides with a 3.7 percent increase in the global real Gross Domestic Product (GDP)" (p. 5). This appears to suggest that states with more wealth available are able to incorporate more international standards in areas such as aviation.

The economic classification of the state into developed and developing was used to show the significant effect GDP has on state implementation of standards. There is evidence that both developing and developed states are more compliant as their GDP increases, although the developed states appear to be the most compliant. The correlation values for the developing states was .111 while that of the developed states was .45 , suggesting that although the developing states do not have a tremendous amount of growth, there is still a small positive correlation. It appears that the wealthiest of the developed states have a greater implementation percentage than the developed states with smaller GDPs, while there is only a slight change in GDP among the developing states as 
implementation increases. The developing states are not as affected by differences in GDP as the developed states. The slope of the correlation of the developed states shows that more available money to spend corresponds to a higher implementation percentage. Because there is a positive correlation between GDP and Effective Implementation percentage, among both developed and developing states it is possible to determine if, after accounting for GDP, there is evidence of a relationship between Effective Implementation and fatalities.

Because GDP does appear to have an effect on the implementation percentage, the next step was to determine if a relationship between Effective Implementation percentage and fatality rate was still evident. The analysis determined, ANOVA, the correlation was significant. The results showed a partial $r$ value of -.224 . The partial correlation statistic was used because the analysis was suggesting the relationship between fatality rate and Effective Implementation rate after accounting for GDP. The results were negative and a medium correlation of -.224 suggests that, even with variations in GDP among states, as Effective Implementation rates increase, fatality rate decreases. An ANOVA was performed on the regression, calculating a $t$ critical value of -3.037 and an associated $p$-value of .003. This $p$-value is lower than the accepted significance level of .05 , indicating significance. This suggests that the slope of the regression line is not equal to 0 ; therefore, it is indicative of a true negative relationship between fatality rate and Effective Implementation. A slope of 0 would indicate a horizontal line, suggesting that as Effective Implementation increases, fatality rates remain the same. The correlation of -.224, however, is negative and significant. 
The results suggest that, even though it may be difficult for the eye to discern a relationship when looking at figure 4.2 , a negative relationship exists between the Effective Implementation percentage and the average fatality per departure. The bar graphs and scatter plots suggest that the larger and wealthier states have, as a whole, larger commercial operations and higher compliance with international standards. However, at the same time, the larger states also account for the highest number of fatalities over a given time period. Despite this, a significant negative correlation appears to convey the importance of compliance to international standards agreed upon by member states. ICAO objectives have a specific emphasis on establishing and maintaining a safe environment. Through the audit and the determined implementation percentage from the protocol questions, ICAO is able to determine areas in which states lack compliance, and emphasize the reduction in fatalities linked to increasing compliance with standards.

\subsection{Recommendations}

Based on this study, the importance of compliance with international standards can be addressed. Despite the size of a state, the wealth of a state, the number of commercial operations, or the number of total fatalities in a given period of time, the more compliant a particular state is with international standards coincides with a reduction in commercial airline fatalities. States need to be informed of this research and understand what the findings suggest. States should make their best efforts to ensure compliance with the international standards set forth by ICAO because of an associated improvement in safety and a reduction in number of fatalities. 
It should also be noted that states should ensure their current regulations are in compliance with international standards and are being enforced. An established standard could have little value if it is not enforced either internally or externally. Compliance with standards should enhance commercial aviation safety, especially as air traffic continues to become more congested and more people fly on a daily basis. As more and larger aircraft are flying around the world, one accident can result in more fatalities than in previous years. Even a single accident can have ramifications that hurt the entire aviation industry, especially as aircraft accidents become highly publicized events.

ICAO should be a leader in the standardization and state compliance with international practices. In March of 2013, ICAO held its Sixth Worldwide Air Transport Symposium at ICAO headquarters in Montreal, Canada. The member states came together to discuss the sustainability of commercial air transport into the 21 st century (ICAO, 2013a). Mr. Roberto Gonzalez, President of the Council of ICAO, noted that, "An Air Transport Conference is convened approximately every ten years. The purpose is to update ICAO policies for the long-term growth of international civil aviation" (p. 1). The ICAO member states should consider holding these events more than once every ten years as technology is subject to rapid change, and existing methods become antiquated and unreliable.

Safety is a top priority for the sustainability of air transport, and compliance with international regulations is a large step towards promoting a safe industry around the globe. It is, however, only one step and the states should continue to cooperate for the benefit of the global aviation industry. It is necessary that states support each other through individual negotiations as well as through ICAO. Aviation is a global industry 
that requires global participation and cooperation. At the Sixth Worldwide Air Transport Conference in Montreal, the participating states recommended in the final report of working paper 1.1 that, " ICAO should be the only forum for initiating global solutions for the development of a sustainable air transport system for all interested parties" (ICAO, 2013b, p. 6). Safety is a key to having a sustainable air transport system in the future and the emphasis on compliance to ICAO standards should not be taken for granted.

\subsection{Future Study}

An effective ICAO implementation rate is only one aspect of aviation safety. This study explored the relationship between implementation of standards and fatalities, not causation. More research needs to be done to explore other factors associated with the implementation rate such as standardization of pilot training and number of accidents. The USOAP conducted by ICAO needs to be investigated to determine if a particular emphasis area lacks state compliance more than others and the possible safety effects associated with that compliance or lack thereof. There may be need for ICAO to improve the audit that addresses the current aviation industry. ICAO is in the process of amending the USOAP. In 2013, ICAO is expecting to transition to a continuous monitoring approach (CMA). ICAO states that, "Overall, the CMA represents the best long-term, cost-effective, resource-efficient, and sustainable approach to safety oversight monitoring" (ICAO, 2010b, p. 28). The CMA will change the USOAP from a one-time evaluation of a state's regulations to a systematic process allowing for continuous evaluation (ICAO, 2010b). As ICAO implements the CMA, research will need to be 
done to evaluate the effectiveness of this new approach compared to the older USOAP, its effect on compliance with ICAO standards, as well as the possible effects on overall safety in the aviation industry. This study only addressed fatalities from commercial accidents and did not evaluate the occurrence of incidents or accidents that did not involve a fatality. There may be more evidence to support the compliance of international standards in other variables besides fatalities. A completely safe aviation industry is more than just one where fatalities are minimized.

\subsection{Summary}

This study addressed the relationship between the Effective Implementation rate of state adherence to international standards and a safe aviation industry (for the purpose of this research, the number of commercial aviation fatalities from 2005 to 2012 was the metric used to evaluate the safety record of a state). The analysis suggested that a negative relationship did exist after standardizing the number of departures and fatalities among ICAO member states. There are currently 191 member states in ICAO, but due to a lack of information only 177 of the member states were analyzed. GDP level appeared to have a positive relationship with Effective Implementation. Accounting for that in an ANOVA with GDP in the model first, followed by Effective Implementation of ICAO standards, the fatality rate still had a negative relationship and the slope had a significance level of less than .05. Lastly, this paper makes recommendations for future study in the area of international aviation policies and standards. 


\section{LIST OF REFERENCES}




\section{LIST OF REFERENCES}

Abeyratne, R.I.R. (1998). Legal and regulatory issues in international aviation. The American Journal of International Law, 92, 175-177.

Axelrod, R. \& Keohane, R.O. (1985). Achieving cooperation under anarchy: Strategies and institutions. World Politics. 38(1), 226-254.

Barnett, M. \& Finnemore, M. (2004). Rules for the world: International organizations in global politics. Ithaca, New York: Cornell University Press.

Bowen, B. D., \& Lu, C-t. (2004). Reporting Airline Safety Performance and the Sensitivity of Airline Safety Factors [CD-ROM]. Safety Across HighConsequence Industries Conference, 9 -10, March, St. Louis, Missouri, USA.

Button, K., Clarke, A., Palubinsaks, G., Stough, R, \& Thibault, M. (2004). Conforming with ICAO safety oversight standards. Journal of Air Transport Management. 10, 251-257.

CBS News. (2012). Plane crashes in Nigeria, all 153 aboard dead. Retrieved from http://www.cbsnews.com/8301-202_162-57446242/plane-crashes-in-nigeria-all153-aboard-dead/.

Cohen, J. (1988). Statistical power analysis for the behavioral sciences (2nd ed.). Hillsdale, NJ: Lawrence Erlbaum. 
Europa. (2011). Press release- aviation: Commission updates the EU list of air carriers subject to an operating ban. Retrieved from http://europa.eu/rapid/pressrelease_IP-11-1375_en.htm.

Federal Aviation Administration. (1994). Advisory circular: United States and international civil aviation organization (FAA Publication No. AC 91-70).

Goldhaber-Fiebert J.D., Lipsitch M., Mahal A., Zaslavsky A.M., \& Salomon J.A. (2010). Quantifying Child Mortality Reductions Related to Measles Vaccination. PLoS ONE 5(11), 1-6. doi:10.1371/journal.pone.0013842.

Gonzalez, R.K. (2013). Opening remarks by the president of the council of ICAO to the sixth worldwide air transport conference. Retrieved from http://www.icao.int/Meetings/atconf6/Documents/ATConf 6_Speech_President.pdf.

Gourdin, K. (1998). U.S. international aviation policy into the new millennium: Meeting the global challenge. Transportation Journal, 37(4), 13-19.

Hamilton, J.S. (2007). Practical aviation law. Newcastle, WA: Aviation Supplies \& Academics, Inc.

International Civil Aviation Organization. (n.d.). Convention on civil international aviation. Retrieved from http://www.icao.int/publications/Pages/doc7300.aspx. International Civil Aviation Organization. (2010a). Implementation indicators. Retrieved from http://www2.icao.int/en/ism/iStars/Pages2/LEI\%20by\%20Area.aspx. International Civil Aviation Organization. (2010b). The USOAP evolved: Realizing the promise of the continuous monitoring approach. ICAO Journal, 5, 25-28. 
International Civil Aviation Organization. (2011). 2011 State of global aviation safety.

Montreal, Canada: International Civil Aviation Organization.

International Civil Aviation Organization. (2012). 2012 Safety report.

Montreal, Canada: International Civil Aviation Organization.

International Civil Aviation Organization. (2013a). Sixth worldwide air transport

conference. Retrieved from

http://www.icao.int/Meetings/atconf6/Pages/default.aspx.

International Civil Aviation Organization. (2013b, March). Agenda item 1.1. Worldwide air transport symposium (ATCONF): Sixth meeting. Conference conducted at the meeting of the International Civil Aviation Organization, Montreal, Canada.

Keohane, R.O. (1984). After hegemony. Princeton, NJ: Princeton University Press.

Keohane, R.O., \& Martin, L.L. (1995). The promise of institutionalist theory. International Security, 20, 39-51.

Kupchan, C.A. (2012). No one's world: The west, the rising rest, and the coming global turn. New York: Oxford University Press.

Meyers, L.S., Gamst, G., \& Guarino, A.J. (2013). Applied multivariate research: Design and interpretation. $\left(2^{\text {nd }}\right.$ ed). Thousand Oaks, CA: Sage Publications, Inc.

Milde, M. (2008). International air law and ICAO. AJ Utrecht, Netherlands: Eleven International Publishing.

Nayar, B.R. (1995). Regimes, power and international aviation. International Organization, 49, 139-170.

Sproull, N.L. (1995). Handbook of research methods: A guide for practitioners and students in the social sciences. $\left(2^{\text {nd }}\right.$ ed). Metuchen, NJ: The Scarecrow Press. 
Talmon, S. (2009). The recognition of the Chinese government and the convention on civil aviation. Chinese Journal of International Law, 8(1), 135-159.

Tucker, R. (1977). The inequality among nations. New York: Basic Books.

U.S. Department of Transportation. (2012). Federal aviation regulations and Aeronautical informational manual. Newcastle, WA: Aviation Supplies \& Acadmeics, Inc.

USA Today. (n.d.) Is air travel safer than car travel? Retrieved from http://traveltips.usatoday.com/air-travel-safer-car-travel-1581.html.

Wells, A. T., \& Rodrigues, C. C. (2004). Commercial aviation safety (4th ed.). New York, NY: McGraw-Hill Combines, Inc.

Warner, R.M. (2013). Applied statistics. (2nd ed). Thousand Oaks, CA: Sage Publications, Inc. 
APPENDICES 
Appendix A: ICAO Member State Data
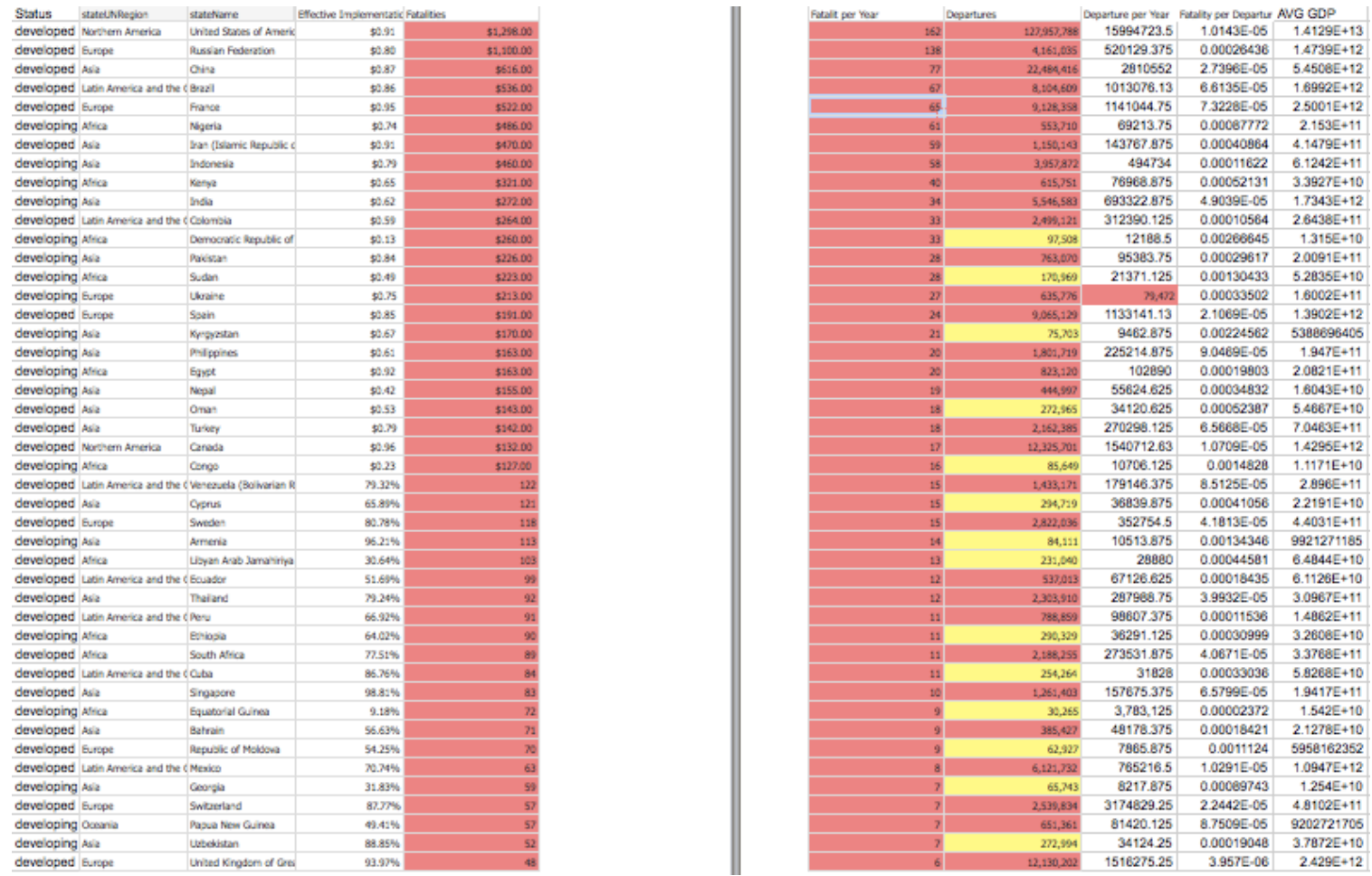

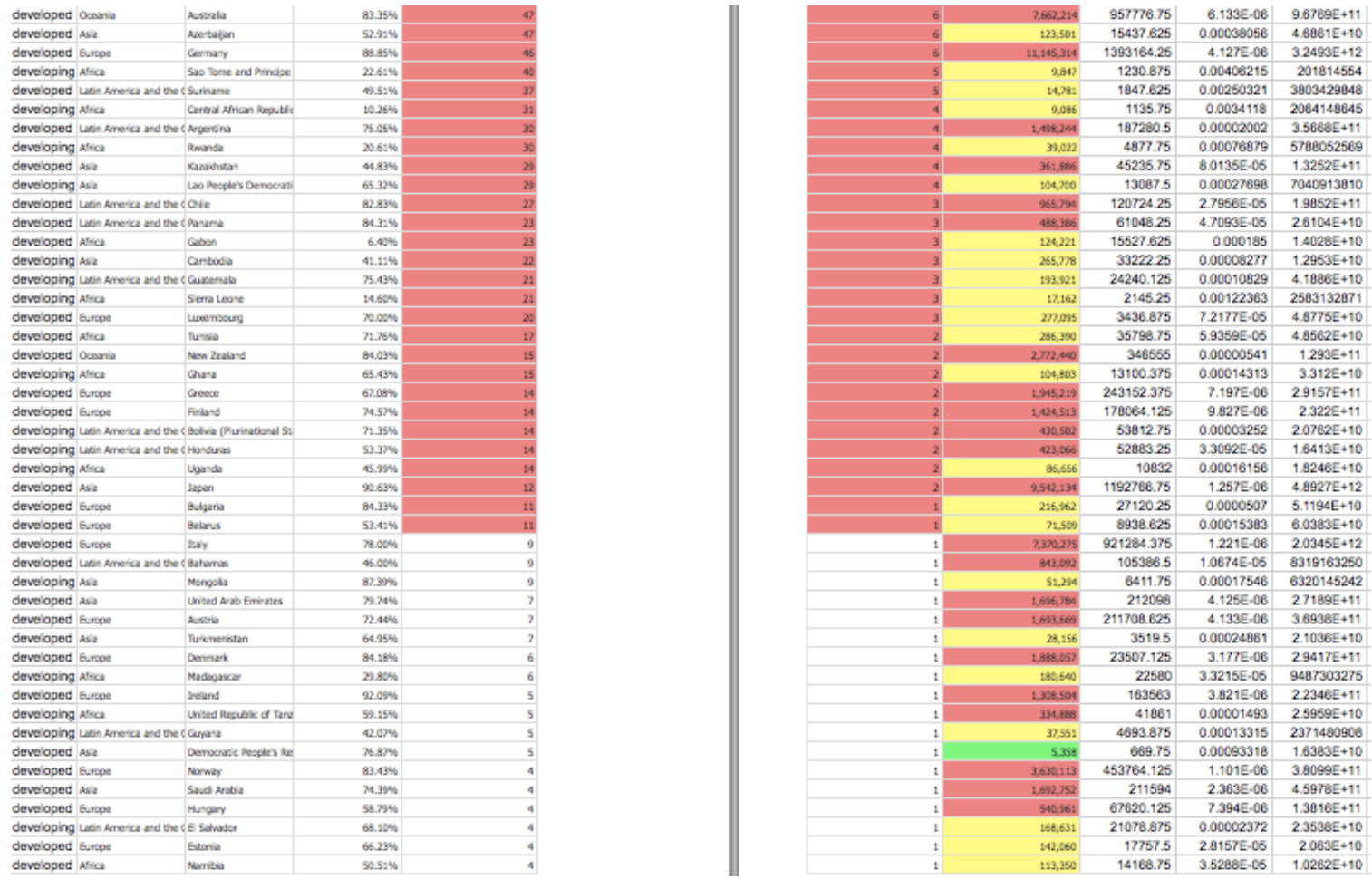

\begin{tabular}{|c|c|c|c|}
\hline developing Ather & opesention & $371 \%$ & \\
\hline developing Labn Areta and the c & Bein & 64.6456 & 3 \\
\hline developed turppe & oows & $73.64 \mathrm{w}$ & 3 \\
\hline developing Atece & Zrtoume & $60.04 \mathrm{~s}$ & 3 \\
\hline developed Eurpe & Sonetia & 76.056 & 3 \\
\hline developing Atha & camerom & $42.95 \%$ & 3 \\
\hline developed Asa & Repusik of Kore: & $98.88 \%$ & 2 \\
\hline developed Ans & Malapia & 81:A15 & 2 \\
\hline developed Eurpe & wand & $87.36 \%$ & 2 \\
\hline developed Gurpet & cooch kxputt: & $86.57 \%$ & 2 \\
\hline developing Ass & Mpermat & $52.17 \%$ & 2 \\
\hline developed ass & ximat: & $83.26 \%$ & 1 \\
\hline developed Ana & bentare & $73.65 \mathrm{~s}$ & 1 \\
\hline developing ocunia & banum & $52.43 \mathrm{~W}$ & 1 \\
\hline developing Atta & Morantique & 22.3656 & 1 \\
\hline developing Atra & Natarent: & 34006 & 1 \\
\hline developing As: & Tequstan & $56.46 \%$ & 1 \\
\hline developed Gurpe & Newnetings & $83.60 \%$ & 0 \\
\hline developed turpe & Donow & 69.065 & 0 \\
\hline developed Gurpe & Begyim & $64.60 \%$ & 0 \\
\hline developing As: & Whe nam & $42.05 \%$ & 0 \\
\hline developing Atica & Merocece & $62.93 \mathrm{~s}$ & 0 \\
\hline developed Lash hreica ad the c & cessa wea & $56.55 \%$ & 0 \\
\hline developed turpe & Remania & $24.23 \%$ & 0 \\
\hline developed Ass & srow & $60.96 \%$ & 0 \\
\hline developing oconis & คy & $62.22 \%$ & 0 \\
\hline developed Asi & Quax & $52.40 \mathrm{N6}$ & 0 \\
\hline developing Asa & Bangadech & $31.62 \%$ & 0 \\
\hline developed Gurpe & Meneso & 43.625 & 0 \\
\hline developed was kneta and the c & touritian kepotic & $86.56 \%$ & 0 \\
\hline developed Lath America and the & denaka & 53.946 & 0 \\
\hline developed Las smeria and thes & 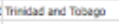 & $73.13 \%$ & 0 \\
\hline developed Gutpe & meand & $81.26 \%$ & 0 \\
\hline developed As & Lebaren & $45.59 \%$ & 0 \\
\hline developing As & 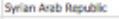 & $51.59 \%$ & 0 \\
\hline developed Eurpe & Setia & $68.50 \%$ & 0 \\
\hline developed turpe & Levia & $64.18 \%$ & 0 \\
\hline developed Atica & Seprelets & $58.25 \%$ & 0 \\
\hline developed Lash Amera and the ch & cartases & 54.2350 & 0 \\
\hline developing Ass & Sil Larita & $86.65 \%$ & 0 \\
\hline developed Lash Aresa and the ch & AActigas and barbuda & $48.35 \%$ & 0 \\
\hline developed turpe & Maka & 69.2450 & 0 \\
\hline developing Atta & Cope verse & $68.35 \%$ & 0 \\
\hline deveioped Gurpe & Uabenis & $67.80 \%$ & 0 \\
\hline developed Ass & Malisves & 56.946 & 0 \\
\hline Seveloping Atha & zamia & $34 . \mathrm{mm}$ & \\
\hline
\end{tabular}

\begin{tabular}{|c|c|c|c|c|}
\hline 1 & $31, x 00$ & 3962.5 & 0.000126 & 1143357578 \\
\hline 0 & 900,158 & 112519.75 & $3.3327 \mathrm{E} .06$ & 1507403037 \\
\hline 0 & $20,8 \in 9$ & 34981 & 0.00001072 & $6.093 E+10$ \\
\hline 0 & 125,006 & 15628.25 & $2.3996 E-06$ & 6379614910 \\
\hline 0 & 12,469 & 15183.625 & 2.4697E-06 & $8.9382 E+10$ \\
\hline 0 & 122,669 & 12833.5 & 0.00002922 & $2.486 E+10$ \\
\hline 0 & 2931,031 & 366378.975 & 6.A2E-07 & 1.0456E+12 \\
\hline 0 & $2,203,310$ & 337913.75 & $7.39 \mathrm{E}-07$ & $2.4497 E+11$ \\
\hline o & L, $, 126,100$ & 139262.5 & 1.796E-06 & $4.7718 E+11$ \\
\hline 0 & 731,753 & 91489.125 & $2.733 E-06$ & $1.9003 E+11$ \\
\hline 0 & 40,614 & 51176.75 & 4.885E-06 & $3.6196 E+10$ \\
\hline 0 & 302,200 & 3775 & 3.309e- -06 & $1.2715 E+11$ \\
\hline 0 & 250,04 & 31263 & $3.99 \mathrm{e}-06$ & $2.306 E+10$ \\
\hline 0 & 146,276 & 18284.5 & 6.836E-06 & 652047053 \\
\hline 0 & $n s, m$ & 18222.125 & 6.859E-06 & 1.11187E+10 \\
\hline 0 & 57,154 & 7144.25 & $1.7496 E .06$ & 5553328758 \\
\hline 0 & 37,379 & 4672.25 & $2.6753 E .06$ & 6096935722 \\
\hline 0 & $2,532,851$ & 316606.375 & 0 & $76076 E+11$ \\
\hline o & $2,474,591$ & 184323.875 & 0 & $2.2762 E+11$ \\
\hline 0 & $2,458,556$ & 183694.5 & 0 & $4.5257 E+11$ \\
\hline 0 & 839,522 & 111191.5 & 0 & 1.1546E+11 \\
\hline o & 628,392 & 78672.75 & 0 & $9.2775 E+10$ \\
\hline 0 & 585,204 & 72850.5 & 0 & $3.2966 E+10$ \\
\hline 0 & 572,355 & 71416.875 & 0 & $1.7094 E+11$ \\
\hline 0 & 529,418 & 6617725 & 0 & 1.9392E+11 \\
\hline 0 & 43,7ns & 54724.375 & 0 & 3607061394 \\
\hline 0 & 436.28: & 57910.125 & 0 & 1. $1063 E+11$ \\
\hline o & 32,902 & 4288.9375 & 0 & 1.0966E+11 \\
\hline 0 & 328,658 & 42332.25 & 0 & 555e0095ee \\
\hline 0 & 336,2000 & 42280 & 0 & $5.1224 E+10$ \\
\hline 0 & $32,3,32$ & 40546.5 & 0 & 1.4216E+10 \\
\hline 0 & 275,796 & 34474.5 & 0 & $2.1824 E+10$ \\
\hline a & 256,305 & 31786.125 & 0 & $1.5232 E+10$ \\
\hline 0 & 236,977 & 29622.125 & 0 & $3.4408 E+10$ \\
\hline 0 & 20,333 & 27541.625 & 0 & $4.7796 E+10$ \\
\hline 0 & 212,943 & 27242.625 & 0 & $4.3151 E+10$ \\
\hline 0 & 213,672 & 26709 & 0 & $2.6699 E+10$ \\
\hline 0 & 228,697? & 26312.125 & 0 & 1142426007 \\
\hline 0 & 283,466 & 25429.5 & 0 & 3960603278 \\
\hline 0 & 127,005 & 22386.875 & 0 & $5.0343 E+10$ \\
\hline 0 & 175,007 & 21875.875 & 0 & 1226902923 \\
\hline 0 & 167,584 & 20939.25 & 0 & 8091107742 \\
\hline 0 & 155,226 & 19778.25 & 0 & 1540227782 \\
\hline 0 & 157040 & 19630.5 & 0 & $4.0326 E+10$ \\
\hline 0 & 163,608 & 17976 & 0 & 1842765997 \\
\hline 0 & 139,583 & 17447.875 & 0 & $1.4495 E+10$ \\
\hline
\end{tabular}




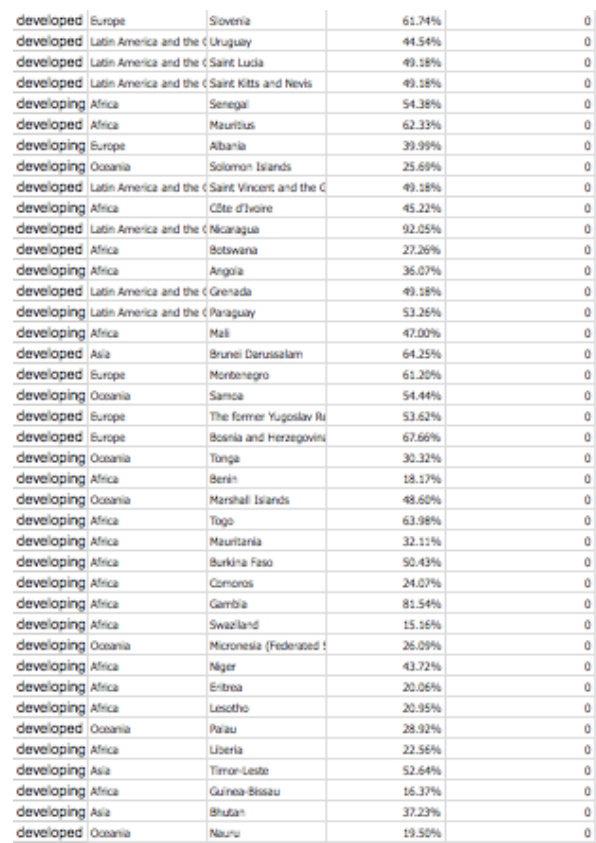

\begin{tabular}{|c|c|c|c|c|}
\hline 0 & 193,453 & 16681.625 & 0 & $4.7501 \mathrm{E}+10$ \\
\hline 0 & 193,319 & 16864.875 & 0 & $3.2611 E+10$ \\
\hline 0 & 129,327 & 16185.875 & 0 & 1263721765 \\
\hline 0 & 126,266 & 15720.75 & 0 & 693078952 \\
\hline 0 & 123,583 & 15447875 & 0 & $1.3649 E+10$ \\
\hline 0 & 120,602 & 1507525 & 0 & $1.0036 E+10$ \\
\hline 0 & 91,978 & 11497.25 & 0 & $1.2997 \mathrm{f}+10$ \\
\hline 0 & 92,573 & 11446.625 & 0 & $767 \mathrm{e} 25880$ \\
\hline 0 & 91,399 & 11422.375 & 0 & 735283289 \\
\hline 0 & 82,253 & 11156.625 & 0 & $2.3327 E+10$ \\
\hline 0 & 86,361 & 10622.625 & 0 & 9309065411 \\
\hline 0 & 84,523 & 10578.375 & 0 & $1.5324 E+10$ \\
\hline 0 & 81,911 & 10238.875 & 0 & $7.4046 E+10$ \\
\hline 0 & non: & 9626.375 & 0 & 855940306 \\
\hline 0 & 72,966 & 9113.25 & 0 & $1.7928 \mathrm{E}+10$ \\
\hline 0 & $x 0,320$ & 8796.25 & 0 & 9172846365 \\
\hline 0 & 65,329 & 8168.125 & 0 & 1.3631E+10 \\
\hline 0 & 63,580 & 7885 & 0 & 4147206038 \\
\hline 0 & 62,2121 & 7886.125 & 0 & 606528024 \\
\hline 0 & 55,126 & 6888.25 & 0 & $1.0163 E+10$ \\
\hline 0 & 53,476 & 6684.5 & 0 & $1.7634 E+10$ \\
\hline 0 & 43,925 & 6115.625 & 0 & 399486625 \\
\hline 0 & 45,250 & 5762.5 & 0 & 7149944787 \\
\hline 0 & 42,593 & 5324.125 & 0 & 150613783 \\
\hline 0 & 42,182 & 5022.75 & 0 & 3359952979 \\
\hline 0 & 36,068 & 4511 & 0 & 3012350026 \\
\hline 0 & 33,961 & 4247.625 & 0 & 9725568385 \\
\hline 0 & 22.361 & 2857.625 & 0 & 563294877 \\
\hline 0 & 21,648 & 2706 & 7.197E-06 & 1161200157 \\
\hline 0 & 20,285 & 2650.625 & 0 & 3547336960 \\
\hline 0 & 12,253 & 2158.625 & 0 & $26749786 \theta$ \\
\hline 0 & 16,0953 & 2011.625 & 0 & 5965319720 \\
\hline 0 & 15,885 & 1985.625 & 0 & 2000270720 \\
\hline 0 & 13,598 & 1692.25 & 0 & 2205343231 \\
\hline 0 & 11,565 & 1445.625 & 0 & 157477430 \\
\hline 0 & 11,478 & 1434.75 & 0 & 1177750646 \\
\hline 0 & 12,459 & 1426.125 & 0 & 19296000000 \\
\hline 0 & 29197 & 1238.625 & 0 & 904306833 \\
\hline 0 & 6.604 & 825.5 & 0 & 1695623056 \\
\hline 0 & 208 & 278.125 & 0 & 45703273.8 \\
\hline
\end{tabular}




\section{Appendix B: ICAO Member States Not Considered}

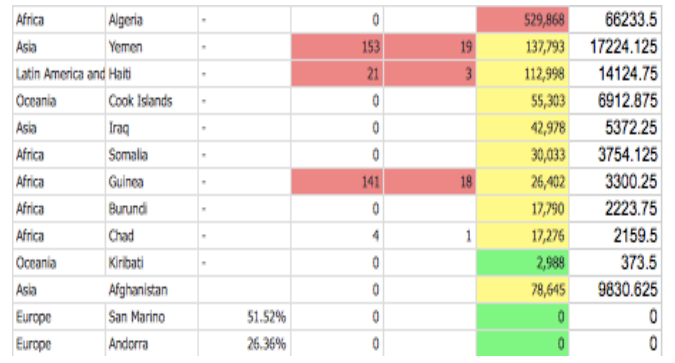

\begin{tabular}{|c|c|c|c|c|c|}
\hline & & Algeria & DZA & $1.0234 E+11$ & $1.1717 E+11$ \\
\hline 0.00111036 & & Yemen, Rep. & YEM & $1.6754 E+10$ & $1.9082 E+10$ \\
\hline \multirow[t]{4}{*}{0.00018584} & & Haiti & HTI & 4154289832 & 4879738636 \\
\hline & & Cook Islands & COK & $182,557,802$ & $187,853,130$ \\
\hline & & Iraq & IRQ & $3.1317 E+10$ & $4.508 E+10$ \\
\hline & & Somalia & SOM & 2315536694 & 2390007510 \\
\hline \multirow[t]{2}{*}{0.0053405} & & Guinea & GIN & 2937072009 & 2821346684 \\
\hline & & Burundi & BDI & 1117254387 & 1237332893 \\
\hline \multirow[t]{5}{*}{0.00023154} & & Chad & TCD & 5301938221 & 6099009023 \\
\hline & & Kiribati & KIR & 105399007 & 104236446 \\
\hline & & Afghanistan & AFG & 6269129359 & 7057055309 \\
\hline & 0.5152 & San Marino & SMR & 1375416604 & 1469075398 \\
\hline & 0.2636 & Andorra & $A D O$ & 2539759286 & 2823503853 \\
\hline
\end{tabular}

*Newest ICAO member state South Sudan not included in data 